\title{
Impact of aromatase inhibitor treatment on global gene expression and its association with antiproliferative response in ER+ breast cancer in postmenopausal patients
}

Qiong Gao ${ }^{1}$, Elena López-Knowles ${ }^{1,2}$, Maggie Chon U. Cheang ${ }^{3}$, James Morden ${ }^{3}$, Ricardo Ribas ${ }^{1}$, Kally Sidhu², David Evans ${ }^{2}$, Vera Martins ${ }^{2}$, Andrew Dodson ${ }^{2}$, Anthony Skene ${ }^{4}$, Chris Holcombe ${ }^{5}$, Elizabeth Mallon ${ }^{6}$, Abigail Evans ${ }^{7}$, Judith M. Bliss ${ }^{3}$, John Robertson ${ }^{8}$, lan Smith ${ }^{9}$, Lesley-Ann Martin ${ }^{1}$, Mitch Dowsett ${ }^{1,2^{*}}$ (iD and on behalf of the POETIC Trial Management Group and Trialists

\begin{abstract}
Background: Endocrine therapy reduces breast cancer mortality by $40 \%$, but resistance remains a major clinical problem. In this study, we sought to investigate the impact of aromatase inhibitor (Al) therapy on gene expression and identify gene modules representing key biological pathways that relate to early Al therapy resistance.

Methods: Global gene expression was measured on pairs of core-cut biopsies taken at baseline and at surgery from 254 patients with ER-positive primary breast cancer randomised to receive 2-week presurgical Al $(n=198)$ or no presurgical treatment (control $n=56$ ) from the POETIC trial. Data from the Al group was adjusted to eliminate artefactual process-related changes identified in the control group. The response was assessed by changes in the proliferation marker, Ki67.
\end{abstract}

Results: High baseline ESR1 expression associated with better Al response in HER2+ tumours but not HER2tumours. In HER2 - tumours, baseline expression of 48 genes associated with poor antiproliferative response $(p<$ 0.005) including PERP and YWHAQ, the two most significant, and the transcription co-regulators (SAP130, HDAC4, and NCOA7) which were among the top 16 most significant. Baseline gene signature scores measuring cell proliferation, growth factor signalling (ERBB2-GS, RET/GDNF-GS, and IGF-1-GS), and immune activity (STAT1-GS) were significantly higher in poor Al responders. Two weeks of Al caused downregulation of genes involved in cell proliferation and ER signalling, as expected. Signature scores of E2F activation and TP53 dysfunction after 2-week Al were associated with poor Al response in both HER2- and HER2+ patients.

Conclusions: There is a high degree of heterogeneity in adaptive mechanisms after as little as 2-week Al therapy; however, all appear to converge on cell cycle regulation. Our data support the evaluation of whether an E2F signatures after short-term exposure to Al may identify those patients most likely to benefit from the early addition of CDK4/6 inhibitors.

Trial registration: ISRCTN, ISRCTN63882543, registered on 18 December 2007.

Keywords: Breast cancer, Oestrogen receptor, Aromatase inhibition, Resistance, Residual proliferation, Signatures

\footnotetext{
* Correspondence: Mitchell.Dowsett@icr.ac.uk

${ }^{1}$ Breast Cancer Now Research Centre, ICR, London, UK

${ }^{2}$ Ralph Lauren Centre for Breast Cancer Research, Royal Marsden Hospital,

London, UK

Full list of author information is available at the end of the article
}

(c) The Author(s). 2019 Open Access This article is distributed under the terms of the Creative Commons Attribution 4.0 International License (http://creativecommons.org/licenses/by/4.0/), which permits unrestricted use, distribution, and reproduction in any medium, provided you give appropriate credit to the original author(s) and the source, provide a link to the Creative Commons license, and indicate if changes were made. The Creative Commons Public Domain Dedication waiver (http://creativecommons.org/publicdomain/zero/1.0/) applies to the data made available in this article, unless otherwise stated. 


\section{Background}

Breast cancer $(\mathrm{BC})$ is the most common malignancy in women worldwide [1]. Over 80\% [2] of primary BCs express oestrogen receptor (ER) alpha. While tamoxifen is an effective agent for reducing recurrence and death from $\mathrm{BC}$, its effectiveness is impeded by its partial agonist activity. Aromatase inhibitors (AIs) show greater efficacy than tamoxifen. They reduce BC mortality by c. $40 \%$ and have become the preferred first-line agent in postmenopausal women [3-5]. While treatment with an AI is sufficient to control the disease in many patients, for others, additional treatment to target resistance pathways is necessary, but identifying the mechanisms of resistance is mandatory to optimise this strategy.

Identifying relevant mechanisms of resistance in individual patients presenting with $\mathrm{ER}+$ primary disease and treated post-surgically with adjuvant AI is prohibitively difficult, because patients are clinically disease-free after surgery and the absence of recurrence may relate to the absence of subclinical micrometastases or to disease control by the AI. In contrast, in the presurgical setting, gene expression in an individual tumour may be assessed in relation to validated markers of response in the same tumour. Multiple clinical trials provide strong evidence to support change in the expression of the nuclear proliferation marker, Ki67, after only 2-week treatment with an endocrine agent to be a valid predictor of the long-term benefit from adjuvant endocrine therapy and to be a better predictor of such benefit than clinical response [6-9]. In addition, the residual level of Ki67 after short exposure to endocrine therapy provides better prognostic information than pretreatment Ki67 [10]. Thus, change in Ki67 can be used to measure a tumour's response to $\mathrm{AI}$ and to study the mechanisms underpinning this, while residual level of Ki67 after short-term AI may be used to identify patients whose tumours retain significant proliferative drive, who are thereby at high-risk of recurrence and merit additional treatment. Identifying the molecular pathways associated with the residual Ki67 may allow such additional treatment to be targeted at relevant resistance pathway(s).

While a small number of presurgical studies have the potential to identify pathways associated with response and early resistance in ER+ patient populations, including some by our group [11, 12], most reports have lacked adequate patient numbers to allow the identification of effects restricted to subgroups of patients. In addition, and importantly, previous reports have not included controls that can identify artefacts that result from the experimental design of pre-surgical studies; we have recently reported that the changes in gene expression of the greatest magnitude in AI-treated patients in a short-term presurgical study are entirely artefactual. This makes the inclusion of a control set of tumours critical for eliminating these artefacts [13]. In the following analyses, we have utilised a study design that avoids these limitations by accessing samples from the PeriOperative Endocrine Therapy-Individualising Care (POETIC, CRUK/07/015) trial [14]. The inclusion of the no-treatment group in POETIC allowed us to adjust our observation in order to eliminate the impact of pre-analytical artefacts.

The POETIC trial, randomised postmenopausal women with primary $\mathrm{ER}+\mathrm{BC} 2: 1$ receive perioperative AI ( 2 weeks pre- + 2 weeks post-surgery, termed AItreated) or no perioperative treatment (termed control). We report analyses from the cohort of 254 (AI-treated = 198; control =56) patients from whom samples in RNAlater were available and provided high-quality genomewide expression data. This is the largest presurgical study of the mechanisms of response and resistance to AIs to date and has sufficient numbers for separate analyses of HER2 - and HER2+ subsets (i) to determine the associations between the baseline expression of individual genes or biological pathways with the change in Ki67 and the residual on-treatment $\mathrm{Ki} 67$ and (ii) to investigate the early impact of AI on gene expression and gene signatures.

\section{Methods}

Detailed methods are described within the STAR file (Additional file 1)

\section{Patients and samples}

The patients studied were a subpopulation of the POETIC (PeriOperative Endocrine-Therapy for Individualised Care) [14] study. The study design is illustrated in Fig. 1a.

\section{RNA extraction}

Total RNA was extracted using miRNeasy (Qiagen, Sussex, UK). RNA quality was checked using an Agilent Bioanalyser (Santa Clara, CA, USA), as previously described [15].

\section{Ethics statement}

Ethical approval for POETIC (Trial Number CRUK/07/ 015) was provided by NRES Committee London-SouthEast. All patients consented to molecular analysis of their samples for research purposes.

\section{Gene expression analysis and data pre-processing}

RNA amplification, labelling, and hybridization on HumanHT-12_V4 expression BeadChips (Illumina, San Diego, CA, USA) were performed, according to the manufacturer's instructions. The raw data was extracted using 

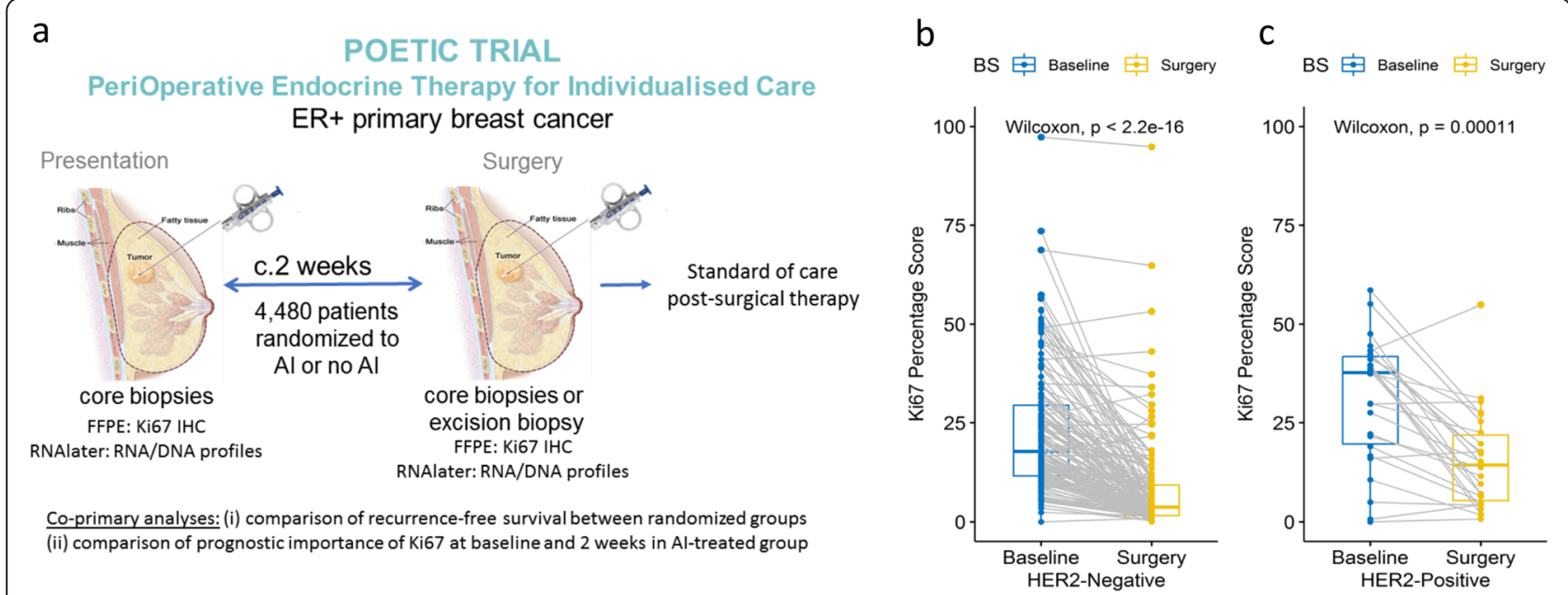

Fig. 1 a POETIC schema, study design POETIC Trial PeriOperative Endocrine Therapy for Individualised Care. b Individual Ki67 changes in HER2$(n=159)$ Al-treated groups. $\mathbf{c}$ Individual Ki67 changes in HER2+ $(n=26)$ Al-treated groups. The boxes indicate the median and interquartile ranges

GenomeStudio Software and was processed in R using lumi package (http://www.bioconductor.org) (Additional file 1).

\section{Elimination of gene expression changes in the control group}

To correct for potential artefactual changes in the gene expression that resulted from study procedures (10), the 2-week changes in the expression resulting from AI treatment were estimated for each gene by comparing the expression changes ( $\log _{2}$ (Surgery/Baseline) in the AI-treated tumours and the expression changes $\left(\log _{2}{ }^{\text {(Surgery/Baseline) }}\right)$ of the un-treated tumours. The relative (corrected) gene expression level in a given sample was calculated by subtracting the mean expression for the gene in the control samples from the expression of the given gene in the AI-treated tumour. All data shown that relate to either ontreatment expression/signature score or changes in the expression/signature score were corrected in this manner.

\section{Biomarker analyses}

Ki67\% staining on formalin-fixed samples was carried out using anti-MIB-1 (M7240, DAKO UK), as previously described (7). HER2 status was measured locally using immunohistochemistry (IHC) and/or in situ hybridisation [16].

\section{Published gene signatures}

We determined the association of gene signatures representative of various biological processes for their association with the antiproliferative response to AI. In some cases, these signatures have been suggested as associated with resistance to endocrine therapy, and the work here can be considered an assessment of the validity of those findings: Inflammatory-GS [11], STAT1-GS [12], IGF1-GS [12], RBloss-GS and DiLeoRBloss-GS [17, 18], E2Factivation-GS [19], E2F4GS [20], TP53-GS [21], and GDNF-GS [22]. For other signatures, our analyses were exploratory, and positive findings would need further validation. Many of the signatures have a predominance of known proliferation-associated genes (PAGs) that obscure the likely relationship with the signalling pathways per se; therefore, we conducted analyses that included and excluded PAGs from the respective signatures, as previously described [12] (Additional file 2: Table S1).

\section{Immune or stromal score estimation}

To allow comparison of the extent of immune or stromal admixture between samples, we used ESTIMATE [23].

\section{Statistical analysis}

Unpaired $t$ tests were used to compare the mean changes in the gene expression $\left(\log _{2}{ }^{\text {[Surgery/Baseline] }}\right)$ of tumours in the treated vs the control group using BRBArray Tools (https://brb.nci.nih.gov/BRB-ArrayTools/). The Ingenuity Pathways Analysis (IPA) was conducted on the lists of genes that associated with the change in $\mathrm{Ki67}$, or residual Ki67, or were differentially expressed to identify over-represented pathways. For individual pathways, the Benjamini-Hochberg procedure was used to calculate the false discovery rate (FDR) in order to adjust for multiple testing; the association between the two groups was considered to be statistically significant when $p$ value $<0.005$; the difference between the two sets of data was considered to be statistically significant when $p$ value $<0.001$. Reported $p$ values are two-sided. 


\section{Endpoints}

Four endpoints were used in this study: (i) change in Ki67 between baseline and 2 weeks as a continuous variable and (ii) responder or non-responder, defined as a reduction of $>60 \%$ or $<60 \%$, respectively [24]; (iii) residual Ki67 as a continuous variable, and (iv) presence or absence of complete cell cycle arrest (CCCA or noCCCA), i.e. residual $\mathrm{Ki} 67<2.7 \%$ or $>$ $2.7 \%$, respectively [25]. Each of the endpoints provides different information: (i) and (ii) reflect the antiproliferative response to $\mathrm{AI}$ treatment which relates to the benefit from the treatment, and endpoints (iii) and (iv) relate to the residual risk after AI therapy as described in a reference endpoints' table (Additional file 2: Table S2). Patients with a baseline Ki67 value $<5 \%$ were excluded from (i) and (ii) because low pretreatment values can lead to highly aberrant estimates of proportional change.

\section{Results}

\section{Patient demographics and changes in Ki67}

There were 198 AI-treated patients with a baseline gene expression profile and paired Ki67 values (Additional file 8). Of these, 157 also had a gene expression profile at surgery. There were 56 controls with a gene expression profile at both baseline and surgery. Reasons for samples being excluded are shown in the consort diagram (Additional file 3: Figure S1). The demographics of the AI-treated patients are shown in Additional file 2: Table S3. Of the tumours, $81 \%$ were ductal and $61 \%$ were histologic grade 2. At surgery, $66 \%$ had a tumour diameter between 2 and $5 \mathrm{~cm}$. All tumours were ER+, except 1 case which was found to be ER-negative after all analyses had been completed. Data on HER2 status, the individual changes in Ki67, and categorisation into responders or non-responders is shown in Additional file 2: Table S4.

Twenty-six (13.1\%) of the AI-treated tumours and 8 (14.3\%) of the control tumours were HER2+. Major between-patient heterogeneity in Ki67 change was evident in both the HER2- and HER2+ AI-treated groups, but there was significantly greater geometric mean suppression of Ki67 in the HER2 - compared to the HER2+ cases $(77.7 \%$ and $50.0 \%$, respectively; $p=2.72 \mathrm{E}-04)$ (Fig. 1b, c). One hundred thirteen of 155 (72.9\%) of the HER2 - cases (with baseline Ki67 > 5\%) were classed as good responders, compared with 9/23 (39.1\%) HER2+ cases (Fisher's exact test $p=2.90 \mathrm{E}-03)$. Furthermore, a higher proportion, $40.0 \%(66 / 161)$, of HER2- cases reached CCCA compared with $11.5 \%(3 / 26)$ of the HER2+ cases (Fisher's exact test $p=4.00 \mathrm{E}-03$ ) (Additional file 2: Table S5 a,b,c). This observation confirms previous studies indicating that the antiproliferative response to AIs is impeded in HER2+ tumours [26, 27].
As a consequence, all further analyses were conducted separately for HER2- and HER2+ subgroups.

\section{HER2-negative tumours \\ Predictors of de novo antiproliferative response to Al Association of individual genes and gene signatures with change in Ki67}

Baseline expression of 123 genes correlated with the 2week change in Ki67 with $p$ value $<0.005$ (Additional file 4: Figure S2; Additional file 2: Table S6). Of note, because the change is a reduction in Ki67, correlations with good response are negatively signed. High expression of 75 genes was associated with better response and 48 genes with poorer response. These 2 sets of genes segregated as the 2 major arms when the 123 genes were subjected to hierarchical clustering. The 6 genes with the strongest correlations were all genes associated with better response, but even for these, the absolute $r$ values were all $<0.40$ (Table 1 ; Additional file 2: Table S6). No further distinct groupings were apparent in the heatmap other than a tendency for non-luminal subtypes to show poorer Ki67 suppression.

Among the 48 genes whose high expression associated with poorer response, PERP (a TP53 apoptosis effector) and YWHAQ (tyrosine 3-monooxygenase/tryptophan 5monooxygenase activation protein) were the top 2 best correlated genes ( $r=0.291$ and 0.290 , respectively), while 3 transcription co-regulators, SAP130, HDAC4, and NCOA7, were among the top 16 most correlated with poor Ki67 repression (Table 1 ).

The most highly correlated of the genes associated with better response was $A C A D V L$ which is related to fatty acid degradation [28]. CCND1 and SCUBE2 which are known to be associated with better response to endocrine therapy $[29,30]$ were among the top 16 best correlated with good suppression of Ki67. ESR1 expression was not correlated with the change in Ki67 after 2 weeks of AI therapy (Table 1; Additional file 5: Figure S3a).

Pathway analysis of the 123 genes identified HIPPO signalling as the most significantly over-represented pathway together with others directly or indirectly related to cell cycle regulation including p53 and p70S6K signalling (Additional file 6: Figure S4).

Of the pre-selected baseline signature scores, only proliferation-based modules (Gene70-GS, GGI-GS, AURKA-GS, CIN70-GS) and Rbloss-GS were significantly correlated with poor Ki67 response and these only weakly so $(r=0.243$ to $r=0.161$, all $p<0.05)$. WntTarget34-GS score was significantly correlated with good response, while TP53-GS score (signature associated with functional TP53) and several previously defined oestrogen signalling signatures approached significance (Additional file 7: Figure S5a; Additional file 8: Table S18A). 
Table 1 Genes whose baseline expression significantly correlated with the change in Ki67 $(p<0.005)$ based on 155 HER2- of the 178 Al-treated samples

\begin{tabular}{|c|c|c|c|c|c|c|c|}
\hline \multirow[t]{2}{*}{ Gene symbol } & \multirow[t]{2}{*}{ Entrez gene name } & \multicolumn{3}{|c|}{ Correlate with change in Ki67 } & \multicolumn{3}{|c|}{ Correlate with residual Ki67 } \\
\hline & & $\begin{array}{l}\text { Rank by correlation } \\
\text { coefficient (rho) }\end{array}$ & Rho & $\begin{array}{l}\text { Parametric } \\
p \text { value }\end{array}$ & $\begin{array}{l}\text { Ranking } \\
\text { by rho }\end{array}$ & Rho & $\begin{array}{l}\text { Parametric } \\
p \text { value }\end{array}$ \\
\hline ESR1 & & NA & -0.11 & 1.70E-01 & NA & -0.16 & 5.30E-02 \\
\hline \multicolumn{8}{|c|}{ Associated with good antiproliferative response } \\
\hline ACADVL & Acyl-CoA dehydrogenase very long & 1 & -0.355 & $6.90 \mathrm{E}-06$ & 1 & -0.419 & $1.00 \mathrm{E}-07$ \\
\hline TRABD & TraB domain containing & 2 & -0.333 & $2.51 \mathrm{E}-05$ & 208 & -0.241 & $2.58 \mathrm{E}-03$ \\
\hline CCND1 & Cyclin D1 & 3 & -0.328 & $3.34 \mathrm{E}-05$ & 294 & -0.226 & $4.69 \mathrm{E}-03$ \\
\hline TRIP6 & Thyroid hormone receptor interactor 6 & 4 & -0.299 & $1.71 \mathrm{E}-04$ & 58 & -0.286 & $3.18 \mathrm{E}-04$ \\
\hline $\mathrm{CTTN}$ & Cortactin & 5 & -0.297 & $1.88 \mathrm{E}-04$ & NA & NA & $>5.00 \mathrm{E}-3$ \\
\hline MRPL23 & Mitochondrial ribosomal protein L23 & 6 & -0.295 & $2.04 \mathrm{E}-04$ & 277 & -0.228 & 4.44E-03 \\
\hline $\mathrm{CCNI}$ & Cyclin I & 7 & -0.289 & $2.81 \mathrm{E}-04$ & 89 & -0.271 & $6.79 \mathrm{E}-04$ \\
\hline $\mathrm{EPHX} 2$ & Epoxide hydrolase 2 & 7 & -0.289 & $2.82 \mathrm{E}-04$ & 8 & -0.356 & $6.30 \mathrm{E}-06$ \\
\hline IMPDH2 & Inosine monophosphate & 9 & -0.288 & $3.00 E-04$ & 114 & -0.264 & $9.45 \mathrm{E}-04$ \\
\hline ARHGEF6 & $\begin{array}{l}\text { Rac/Cdc42 guanine nucleotide exchange } \\
\text { factor } 6\end{array}$ & 10 & -0.283 & $3.70 E-04$ & NA & NA & $>5.00 \mathrm{E}-3$ \\
\hline $\mathrm{ACY} 1$ & Aminoacylase 1 & 10 & -0.283 & $3.73 E-04$ & 86 & -0.272 & $6.53 \mathrm{E}-04$ \\
\hline EIF3G & $\begin{array}{l}\text { Eukaryotic translation initiation factor } 3 \\
\text { subunit } \mathrm{G}\end{array}$ & 12 & -0.282 & $3.91 \mathrm{E}-04$ & 122 & -0.261 & $1.08 \mathrm{E}-03$ \\
\hline GLI3 & GLI family zinc finger 3 & 12 & -0.282 & $3.97 \mathrm{E}-04$ & 155 & -0.252 & $1.59 \mathrm{E}-03$ \\
\hline TTC17 & Tetratricopeptide repeat domain 17 & 14 & -0.279 & 4.70E-04 & 6 & -0.366 & $3.30 \mathrm{E}-06$ \\
\hline SCUBE2 & $\begin{array}{l}\text { Signal peptide, CUB domain and EGF-like } \\
\text { domain containing } 2\end{array}$ & 15 & -0.276 & $5.24 \mathrm{E}-04$ & 3 & -0.393 & $5.00 \mathrm{E}-07$ \\
\hline MRPS27 & Mitochondrial ribosomal protein S27 & 16 & -0.274 & $5.84 \mathrm{E}-04$ & 245 & -0.236 & $3.23 \mathrm{E}-03$ \\
\hline \multicolumn{8}{|c|}{ Associated with poor antiproliferative response } \\
\hline PERP & PERP, TP53 apoptosis effector & 1 & 0.291 & $2.53 \mathrm{E}-04$ & 161 & 0.273 & $6.09 \mathrm{E}-04$ \\
\hline YWHAQ & $\begin{array}{l}\text { Tyrosine 3-monooxygenase/tryptophan } \\
5 \text {-monooxygenase activation protein theta }\end{array}$ & 2 & 0.29 & 2.63E-04 & 86 & 0.328 & $3.47 \mathrm{E}-05$ \\
\hline SNIP1 & Smad nuclear interacting protein 1 & 3 & 0.275 & 5.47E-04 & 210 & 0.26 & $1.15 \mathrm{E}-03$ \\
\hline PNO1 & Partner of NOB1 homologue & 4 & 0.274 & $5.74 \mathrm{E}-04$ & 214 & 0.258 & $1.21 \mathrm{E}-03$ \\
\hline SEC22B & $\begin{array}{l}\text { SEC22 homologue B, vesicle trafficking } \\
\text { protein (gene/pseudogene) }\end{array}$ & 5 & 0.268 & 7.64E-04 & NA & NA & $>5.00 \mathrm{E}-3$ \\
\hline GOLT1B & Golgi transport 1B & 5 & 0.268 & $7.92 \mathrm{E}-04$ & 87 & 0.326 & $3.82 \mathrm{E}-05$ \\
\hline SAP130 & Sin3A-associated protein 130 & 7 & 0.264 & $9.56 \mathrm{E}-04$ & 285 & 0.24 & $2.65 \mathrm{E}-03$ \\
\hline GPKOW & G-patch domain and KOW motifs & 8 & 0.261 & $1.08 \mathrm{E}-03$ & 135 & 0.289 & $2.78 \mathrm{E}-04$ \\
\hline NUS1 & $\begin{array}{l}\text { NUS1 dehydrodolichyl diphosphate } \\
\text { synthase subunit }\end{array}$ & 9 & 0.259 & 1.19E-03 & 187 & 0.266 & 8.67E-04 \\
\hline PLCB1 & Phospholipase $\mathrm{C}$ beta 1 & 10 & 0.257 & $1.28 \mathrm{E}-03$ & NA & NA & $>5.00 \mathrm{E}-3$ \\
\hline MBIP & MAP3K12 binding inhibitory protein 1 & 11 & 0.256 & $1.34 \mathrm{E}-03$ & NA & NA & $>5.00 \mathrm{E}-3$ \\
\hline VCAM1 & Vascular cell adhesion molecule 1 & 12 & 0.254 & $1.50 \mathrm{E}-03$ & 132 & 0.29 & $2.62 \mathrm{E}-04$ \\
\hline DNAJC8 & $\begin{array}{l}\text { Dnaj heat shock protein family (Hsp40) } \\
\text { member } \mathrm{C} 8\end{array}$ & 13 & 0.25 & $1.79 \mathrm{E}-03$ & NA & NA & $>5.00 \mathrm{E}-3$ \\
\hline HENMT1 (C1orf59H) & EN methyltransferase 1 & 14 & 0.249 & 1.87E-03 & 201 & 0.261 & $1.08 \mathrm{E}-03$ \\
\hline MRPL50 & Mitochondrial ribosomal protein L50 & 15 & 0.246 & 2.07E-03 & NA & NA & $>5.00 \mathrm{E}-3$ \\
\hline ODF2 & Outer dense fibre of sperm tails 2 & 16 & 0.245 & $2.15 \mathrm{E}-03$ & NA & NA & $>5.00 \mathrm{E}-3$ \\
\hline PIGA & $\begin{array}{l}\text { Phosphatidylinositol glycan anchor } \\
\text { biosynthesis class A }\end{array}$ & 16 & 0.245 & $2.16 \mathrm{E}-03$ & 209 & 0.26 & $1.13 \mathrm{E}-03$ \\
\hline HDAC4 & Histone deacetylase 4 & 16 & 0.245 & $2.19 E-03$ & 311 & 0.236 & $3.21 \mathrm{E}-03$ \\
\hline
\end{tabular}


Table 1 Genes whose baseline expression significantly correlated with the change in Ki67 $(p<0.005)$ based on 155 HER2- of the 178 Al-treated samples (Continued)

\begin{tabular}{|c|c|c|c|c|c|c|c|}
\hline \multirow[t]{2}{*}{ Gene symbol } & \multirow[t]{2}{*}{ Entrez gene name } & \multicolumn{3}{|c|}{ Correlate with change in Ki67 } & \multicolumn{3}{|c|}{ Correlate with residual Ki67 } \\
\hline & & $\begin{array}{l}\text { Rank by correlation } \\
\text { coefficient (rho) }\end{array}$ & Rho & $\begin{array}{l}\text { Parametric } \\
p \text { value }\end{array}$ & $\begin{array}{l}\text { Ranking } \\
\text { by rho }\end{array}$ & Rho & $\begin{array}{l}\text { Parametric } \\
p \text { value }\end{array}$ \\
\hline NCOA7 & Nuclear receptor coactivator 7 & 16 & 0.245 & $2.21 \mathrm{E}-03$ & NA & NA & $>5.00 \mathrm{E}-3$ \\
\hline
\end{tabular}

The genes of top rank 16 that associated with good antiproliferative response and the genes of top rank 16 that associated with poor antiproliferative response, plus ESR1. All the 123 genes showing a significant correlation with the change in Ki67 are shown in Additional file 2: Table S5

When the Ki67 changes were dichotomised to responders and non-responders, most of the baseline GSs whose score significantly associated with poor response were proliferation-based modules and Rbloss signatures, which was similar to the above. However, four additional GS that are not directly associated with proliferation but rather represent growth factor signalling pathways were significantly higher in non-responder tumours: ERBB2-GS, IGF1-GS, STAT1-GS, GDNF-GS (Table 2; Additional file 2: Table S7). Furthermore, five genes (CCND1, EPHX2, TRIP6, IMPDH2, and $A C A D V L)$ showed baseline expression that was significantly higher in $\mathrm{AI}$ responder tumours $(p \leq 1.5 \mathrm{E}-4)$;

\section{Association of baseline gene expression and pre-selected signatures with 2-week residual Ki67}

Baseline expression of 678 genes correlated with residual Ki67 after AI treatment. High expression of 376 genes was associated with high residual proliferation, and 302 genes were associated with low residual proliferation (Additional file 2: Table S8). Consistent with its association with good Ki67 suppression, ACADVL was the gene whose baseline expression was most strongly associated with low residual Ki67 $(r=0.419)$ and SCUBE2 the third most strongly associated (Table 1). Interestingly, the baseline expression of ACADVL and SCUBE2 was significantly correlated $(r=0.27, p=0.0006)$. ESR1 expression was not correlated with residual Ki67 $(r=-$ $0.16, p=5.3 \mathrm{E}-2$; Table 1; Additional file 5: Figure S3b).

The gene whose baseline expression was most strongly associated with high residual Ki67 was NEK2, a kinase involved in centrosome separation and bipolar spindle formation $(r=0.478)$. PTTG1 and the related PTTG3P were also among the top 5 most strongly correlated with residual Ki67 $(r=0.459$ and 0.477 , respectively). Both code for the members of the securin family that are homologues of yeast proteins that prevent separation of sister chromatid. Similarly, CDCA5, the third most strongly correlated gene, is also a regulator of sister chromatid cohesion, and all other genes strongly correlated at baseline with residual Ki67 are known to be associated with proliferation. Consistent with this, pathway analysis of the 678 genes showed p53, ATM, and EIF2 signalling pathways were among the most significantly over-represented (Additional file 2: Table S9), and of the pre-selected signatures, TP53-GS baseline score was the strongest inversely associated with residual $\mathrm{Ki67}(r=-$ $0.46, p<0.0001$ ) (Additional file 7: Figure S5a; Additional file 8: Table S18A). The inverse correlation relates to high TP53-GS score being associated positively with TP53 wild-type status [21]. In contrast, baseline scores of Gene70-GS, GGI-GS, Rbloss-GS, DiLeoRBlossGS, CIN70-GS, E2F4activation-GS, E2FmotifCellCycleAssociated-GS, AURKA-GS, PTEN-GS, and E2FactivationGS score were positively correlated with residual Ki67 (all $r \geq 0.35, p<\mathrm{E}-05$ ).

As expected, higher baseline signature scores of PIK3CA-GS and modules measuring oestrogen signalling (ERGs-GS, ESR1-1-GS, ESR1-2-GS, SET-GS) were significantly associated with lower residual Ki67 (all $p<0.01$ ). Higher STAT1-GS score was significantly but weakly correlated with higher residual Ki67 $(r=0.19, p=1.57 \mathrm{E}$ -02) (Additional file 7: Figure S5a; Additional file 8: Table S18A).

\section{Association of genes and pre-selected signatures with complete cell cycle arrest}

The baseline gene expression of 129 genes was significantly different between tumours reaching CCCA and noCCCA. Of the 109 genes whose baseline gene expression was significantly higher in the noCCCA tumours, 71.5\% were proliferation-associated (Fig. 2; Additional file 2: Table S10). Similar to the above analysis of associations with residual proliferation, high baseline expression of PTTG1, PTTG3P, NEK2, and CDCA5 were prominent in being associated with noCCCA, but the most noticeable were $T O P 2 A$ and $U B E 2 C$. High baseline NEK2 expression was also associated with poor antiproliferative response (Additional file 4: Figure S2). Notably, 5 genes (SCUBE2, $F C G B P, E F C A B 4 A, E P H X 2$, and BTRC) whose baseline expression was significantly higher in tumours that achieved CCCA (Fig. 2; Additional file 2: Table S10) were also associated with good antiproliferative response (Additional file 4: Figure S2; Additional file 2: Table S6). Furthermore, $A C A D V L$ baseline expression was higher in CCCA tumours $(p=0.001)$.

Of the pre-selected signatures, the baseline expression of TP53-GS, PIK3CA-GS, and ERGs-GS were significantly lower in noCCCA tumours. The lower TP53-GS score associated positively with dysfunctional TP53. In contrast, the expression of GGI-GS, DiLeoRBloss-GS, 


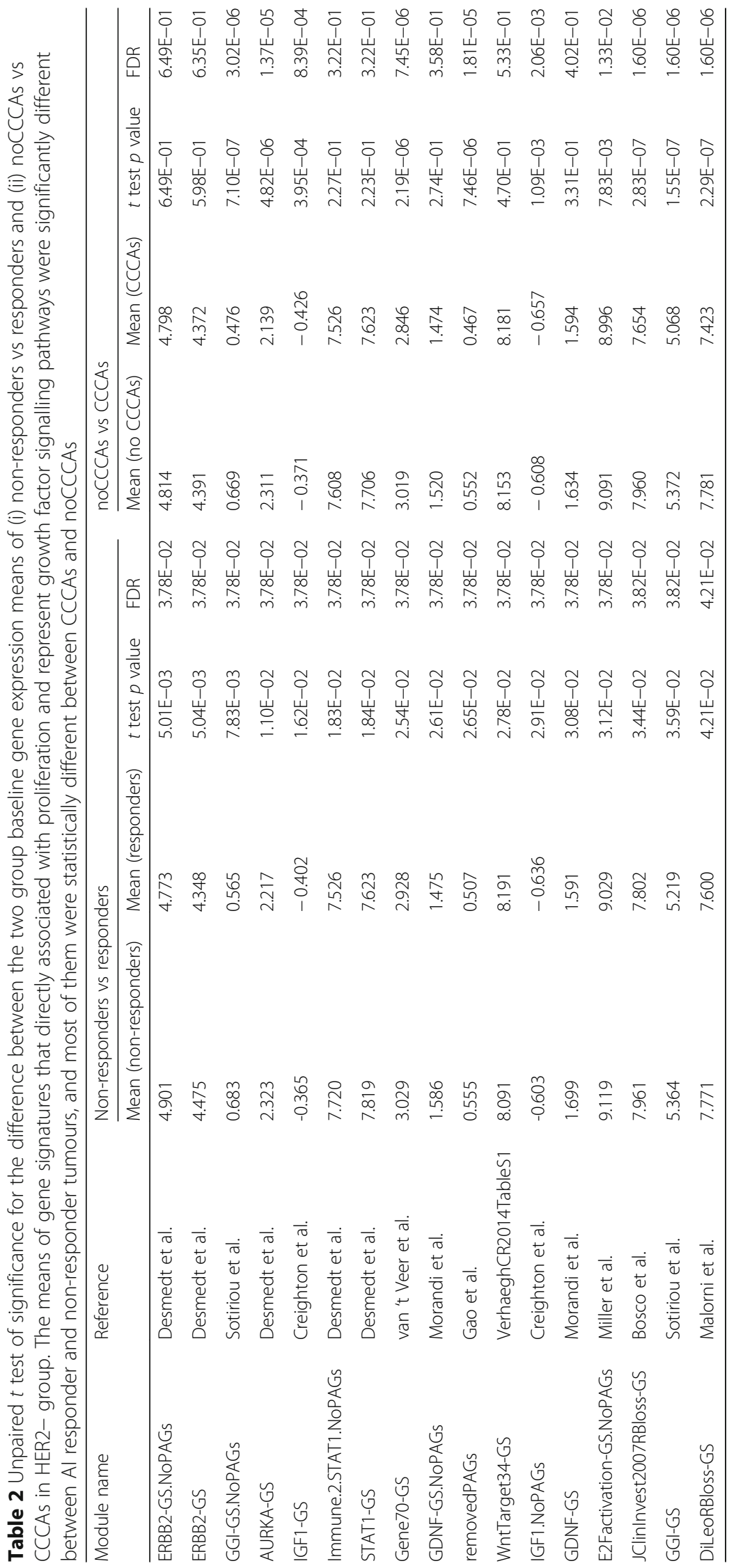




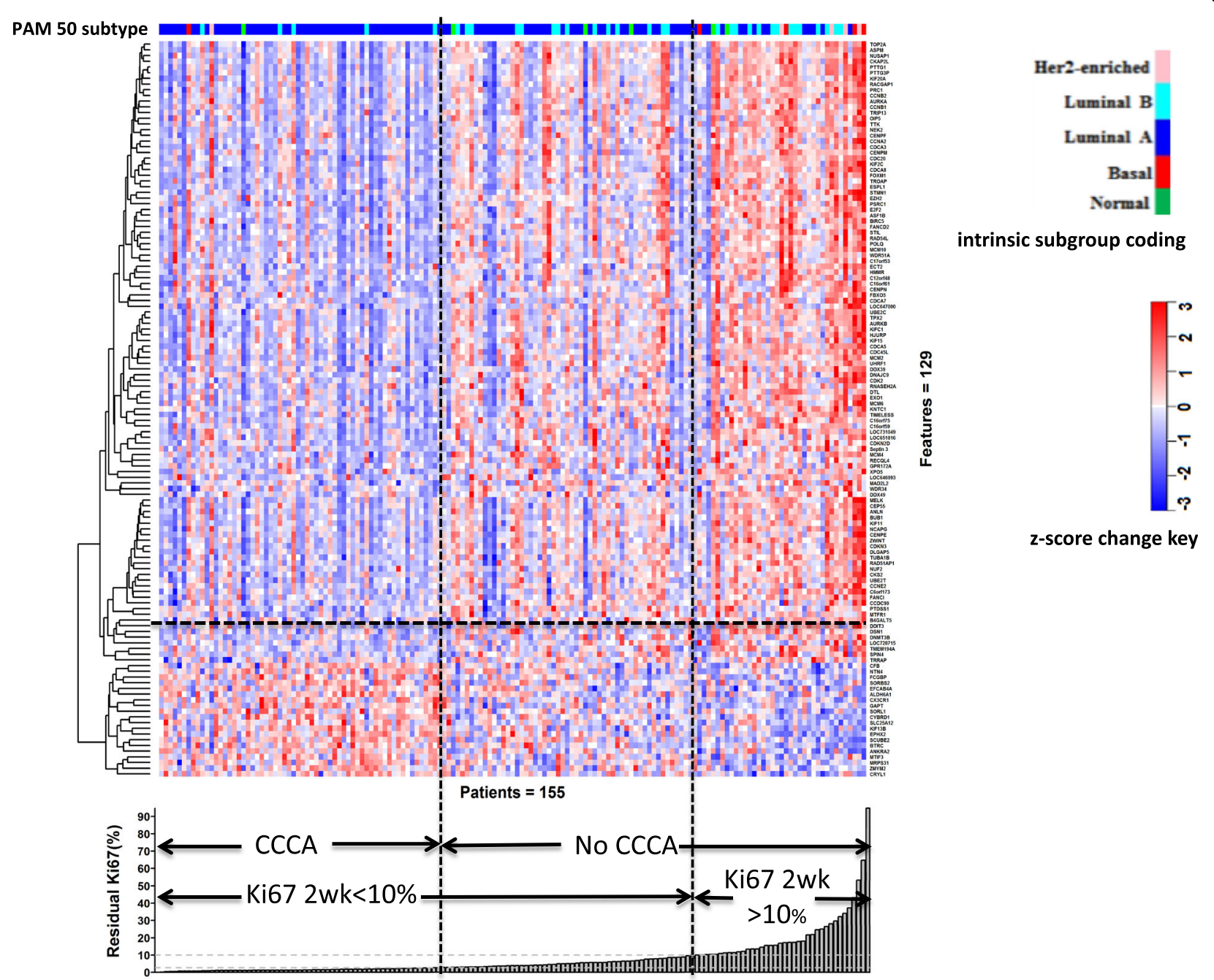

Fig. 2 Heatmap (Pearson, complete) of 129 genes whose baseline expression is significantly different $(p<0.001)$ between CCCA and noCCCA based on 155 HER2 - of the 178 Al-treated samples. The gene expression across 155 samples was centred and scaled. Red denotes the gene expression in a sample is greater than the mean, blue denotes less than the mean. The tumours are ordered according to the residual level of Ki67

Rbloss-GS, CIN70-GS, E2FmotifCellCycleAssociated-GS, Gene70-GS, E2F4activation-GS, AURKA-GS, PTEN-GS, E2Factivation-GS, and IGF1-GS were significantly higher in the noCCCA tumours (all $p<0.0001$ ) (Table 2; Additional file 2: Table S7).

One-dimensional clustering based on the relative baseline gene expression showed no distinct gene groups were apparent, and 5 of the 10 non-luminal tumours (excluding the normal-like) showed poorer than average Ki67 response to AI (Additional file 4: Figure S2). Of the 38 patients who had residual Ki67 (>10\%), 14 were from the original 33 (42\%) luminal B tumours, 4 out of $5(80 \%)$ were HER2-enriched, and 4 out of 5 (80\%) were basal-like. Surprisingly, $13 \%$ of the original luminal A tumours (14 of the 106) were evident (Fig. 2).
Effects of oestrogen deprivation by Al treatment on gene expression and associated pathways

Oestrogen deprivation leads to profound effects on gene expression within 2 weeks. The expression of 902 genes was significantly changed: 560 downregulated and 342 upregulated (Fig. 3a; Additional file 2: Table S11). The most downregulated gene based on the amplitude of change was TFF1, followed by $U B E 2 C$ and TOP $2 A$, whose baseline expression was the most associated with noCCCA (both by $>60 \%$ ). Similarly, NEK2 the gene most associated with residual Ki67 as a continuous variable was the ninth most downregulated gene.

Forty-nine of the top 50 genes that showed the greatest change in expression were downregulated by AI. The large majority of these were either related to proliferation or regulated by oestrogen. NDP was the only upregulated 

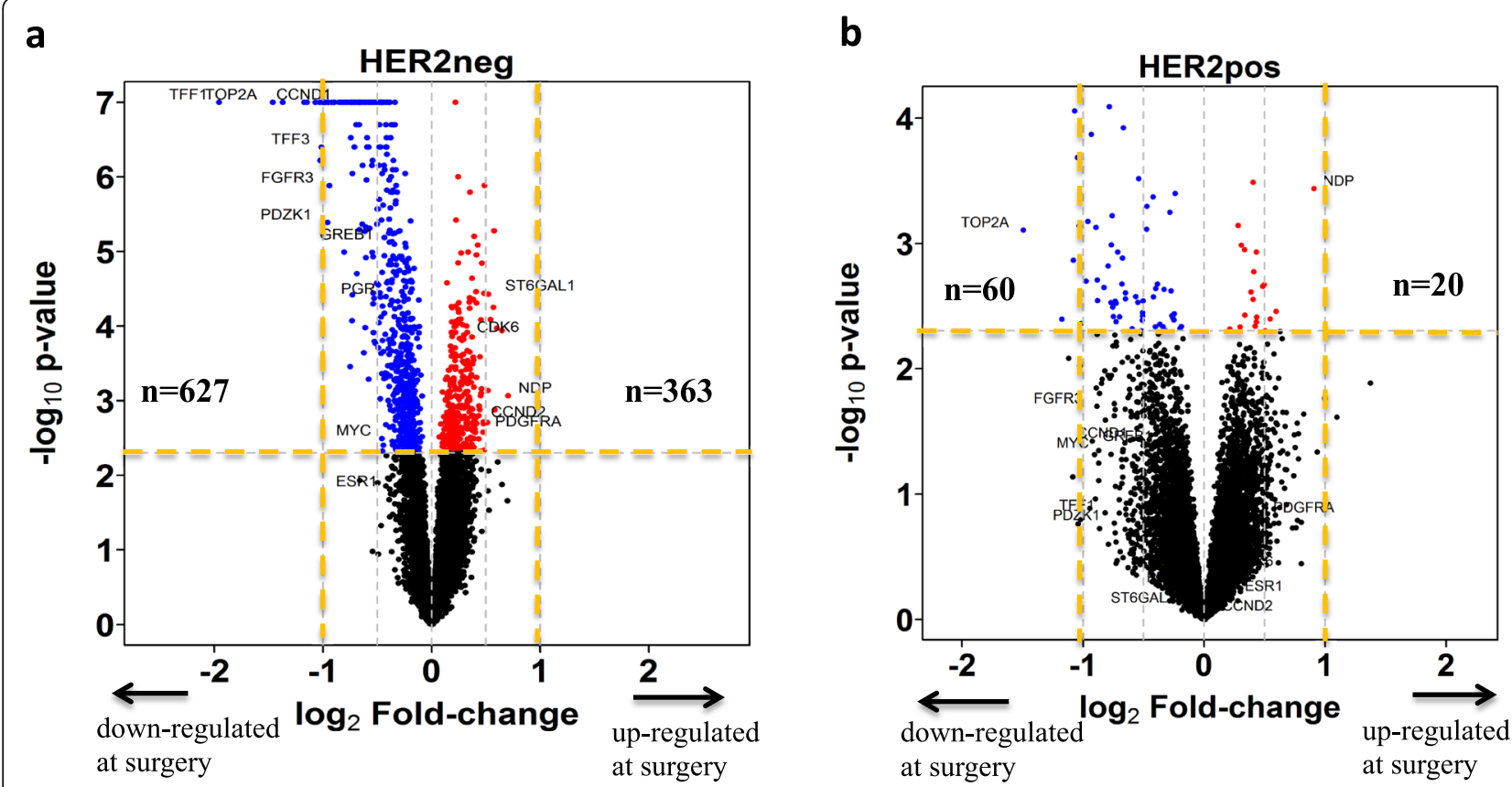

Fig. 3 Volcano plot highlighting the genes that were identified differentially expressed $(p<0.005)$ after Al treatment. Based on the difference of the expression mean changes (log $2^{(\text {Surgery/Baseline) }}$ ) of paired samples between Al-treated and control. a Nine hundred ninety genes $(n=363$ upregulated, $n=627$ downregulated) in HER2- tumours (902 annotated genes). Number of Al-treated pairs, $n=135$; control pairs, $n=46$. $\mathbf{b}$ Eighty genes ( $n=20$ upregulated, $n=60$ downregulated) in HER2+ tumours (71 annotated genes). Number of Al-treated pairs, $n=22 ;$ control pairs, $n=$ 8. The $p$ values range from 1 to a limited minimum value of $1.0 \mathrm{E}-07$ was shown on the $y$-axis in a scale of $-\log _{10}(p$ value)

gene based on the amplitude of change $(\mathrm{FC}=1.63, p=$ 8.69E-04). NDP is a norrin cystine knot growth factor, which activates the canonical Wnt signalling pathway through the frizzled family of receptors $(F Z D)$. Of note, $F Z D 7$, frizzled class receptor 7 was also upregulated $(F C=$ 1.23, $p=0.0002$ ) [31]. Furthermore, THRA, thyroid hormone receptor, was highly upregulated by AI (Additional file 2: Table S12).

The heterogeneity of the changes in the gene expression between patients, irrespective of the change in Ki67, is illustrated in Fig. 4a. A large number of distinct groups of tumours were apparent, but these groups show a little distinct relationship with intrinsic subgrouping or both the change in Ki67 and residual Ki67 levels.

Pathway analysis of the 902 genes that significantly changed with treatment revealed enrichment of 25 canonical pathways (adjusted $p$ value $<0.05$; Fig. 4b; Additional file 2: Table S13), the majority of which were proliferation-related. Cyclin-dependent kinases (CDK1, 2, and 6), CHEK1, cyclins (CCNE1, 2; $C C N D 1,2$; and $C C N B 1,2$ ), and transcription factors $E 2 F 2$ and $E 2 F 5$, which were prominent in the majority of the 25 pathways, were also identified (Additional file 9: Figure S6).

Of particular note, CDK6 and CCND2 were significantly upregulated $(p=1.33 \mathrm{E}-04, p=1.79 \mathrm{E}-03$; Additional file 2: Table S12). In contrast to most of the cyclins and $C D K s, C C N D 2$ is a cell cycle regulator whose activity is dependent on its binding to CDK4/6 in G1 phase. Phosphorylation of $\mathrm{Rb}$ (retinoblastoma) by CDK4/6-CCND2 uncouples Rb from $E 2 F$ allowing transcription of essential S-phase genes. Inhibition of CDK4/ 6-CCND2 in ER+ cells reduces cell proliferation and colony formation via a G1 cell cycle arrest [32]. The upregulation of CCND2 and CDK6 expression after AI therapy may be indicative of early tumour re-wiring that relates to residual proliferation.

Among the upregulated genes after AI treatment (Tables 3, 4, and 5; Additional file 2: Table S11), several (SNAI2, TGFB3, TGFBR2, TWIST2, PDGFD, PDGFRA, and $S M A D 4$ ) are known to contribute to the loss of Ecadherin, a key mechanism in the stabilisation of the mesenchymal state that plays a role in the epithelialmesenchymal transition (EMT) [33]. In addition, the increasing expression of TGFBR2, ACVR1, TGFB3, $S M A D 4$, and $I N H B B$ are all linked to the activation of TGF- $\beta$ signalling $(z$-score $=2.236) \quad$ (Additional file 2 : Table S13); the TGF- $\beta$ signalling pathway has an established role in promoting EMT by downregulating Ecadherin via a number of transcription factors, such as Twist and Slug [34]. Finally, FRMD6 and YAP1, members of the HIPPO pathway, were upregulated, while LATS1/2, known negative regulators of the pathway [35], were undetectable (Additional file 2: Table S11). 


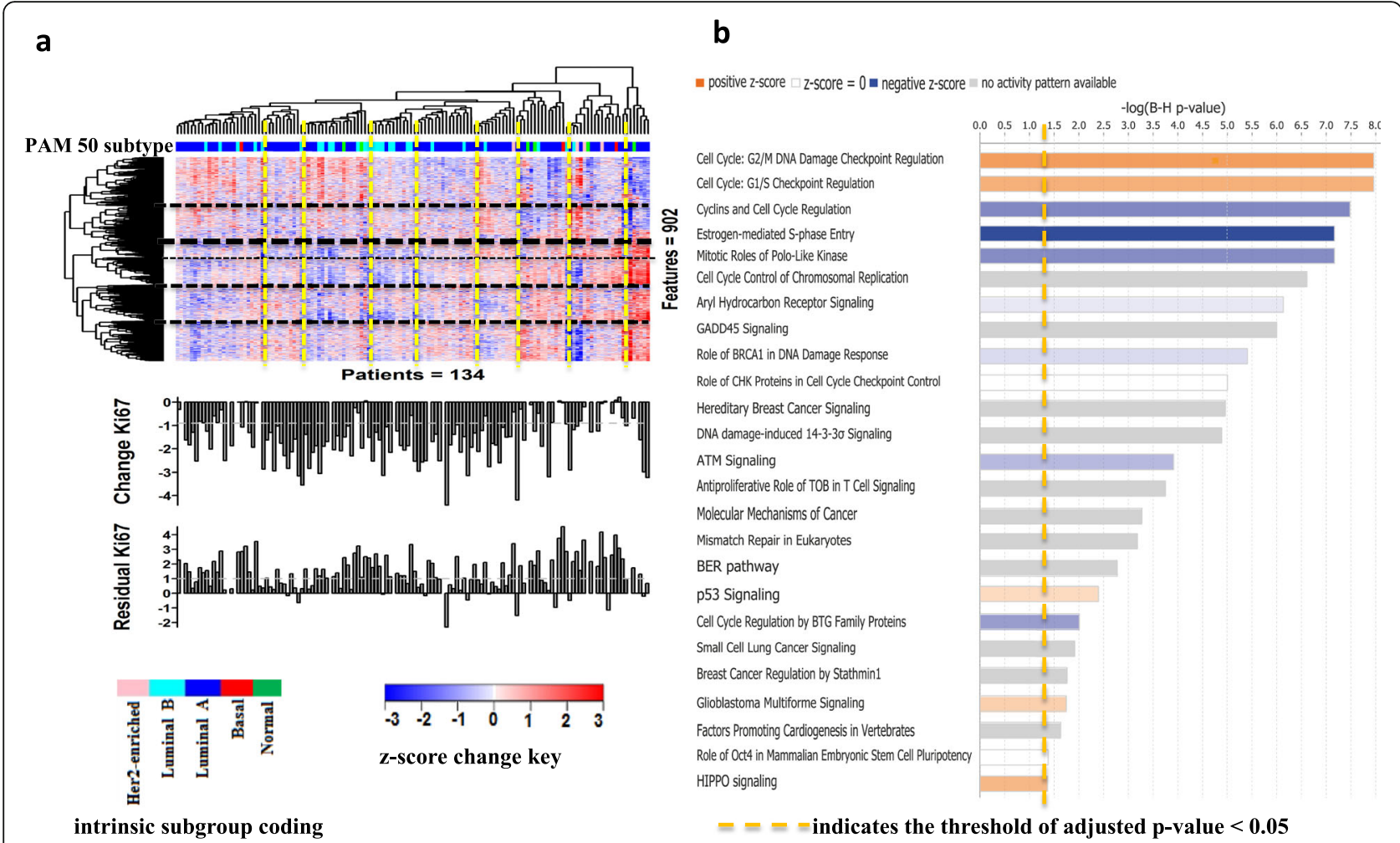

Fig. 4 Unsupervised hierarchical clustering (Pearson, ward.D2) of 902 genes whose expression was significantly regulated after 2 weeks of treatment in HER2 - tumours. And the overrepresented pathways (FDR $<5 \%$ ) identified by pathway analysis (IPA). a The relative change in the gene expression across 134 HER2 - tumours was standardised (centred and scaled). Red denotes the standardised $z$-score $>0$, an increase in gene expression in a tumour after Al treatment compared to the average "relative changes" of the gene across all the 134 tumours; blue denotes the standardised $z$-score $<0$, a decrease in gene expression in a tumour after Al treatment compared to the average "relative changes" of the gene across all the 134 tumours. b The 25 canonical pathways were significantly enriched (FDR $<5 \%$ ). Positive $z$-score shown in orange colour specifies activated pathways; negative $z$-score shown in blue colour specifies inhibited pathways after Al treatment

We next assessed the dynamic changes in the preselected signature response to 2-week AI treatment. ESR1 gene expression and ER-regulated/targeted genes (ERG-GS, ERTarget27-GS, and several proliferationassociated GSs were profoundly reduced by AI (\% $\Delta$ of geometric mean $>10 \%)$ ), but none to the same magnitude as the single IHC marker Ki67 (Table 3; Additional file 2: Table S5). Module scores of Gene70-GS, SET-GS, MYC-GS, PTEN-GS, and IGF1-GS were also all significantly suppressed but to a lesser degree. In contrast, the scores of Stroma.1-GS and TP53-GS had largely increased due to oestrogen deprivation. The increased TP53-GS score associated positively with TP53 wild-type status.

\section{Association of 2-week pre-selected gene signature scores with changes in Ki67 and residual Ki67}

On-treatment gene expression may be at least as important a determinant of resistance to AI therapy and a potential target for additional treatment as pre-treatment gene expression. We therefore assessed the association of on-treatment scores of the pre-selected signatures with the change in Ki67 and residual Ki67 (Table 4; Additional file 10: Figure S7a; Additional file 8: Table S19A). Significant correlations were found with several of the signatures and residual Ki67, and most of these were also significant for change in Ki67. Those correlations significant for both endpoints were (i) the two RB loss signatures [17, 18], (ii) proliferation-related signatures (GGI-GS, CIN70-GS, Gene70-GS, AURKA-GS), (iii) modules measuring oestrogen signalling (SET-GS, ESR1.1-GS, ESR1.2-GS, ERTarget27-GS), (iv) E2F signatures [19, 20], and (v) TP53-GS, PI3K-GS, PTEN-GS, $A K T / m T O R-G S$, and IGF1-GS. Of note, while high ontreatment oestrogen signalling module scores associated with lower residual proliferation and better antiproliferative response, high TP53-GS score that reflects wild-type TP53 function showed the highest correlation.

We found no significant relationship between the change in Ki67 and immune response gene signatures including Inflammatory-GS and the immune and stromal scores estimated by ESTIMATE. However, high 
Table 3 Relative changes in the expression of gene signatures in response to the 2-week Al treatment of the HER2- and HER2+ tumours.

\begin{tabular}{|c|c|c|c|c|c|}
\hline \multirow[t]{2}{*}{ Module name } & \multicolumn{2}{|l|}{ HER2-negative } & \multicolumn{2}{|l|}{ HER2-positive } & \multirow{2}{*}{$\begin{array}{l}\text { Significance of the } \\
\text { difference between } \\
\text { two changes in } \\
\text { expression } \\
\text { (HER2-vs HER2+) }\end{array}$} \\
\hline & $\begin{array}{l}\% \Delta \text { of geometric } \\
\text { mean of intensities } \\
\text { of a module of pre- } \\
\text { and post-treatment }\end{array}$ & $\begin{array}{l}\text { 2-sided unadjusted } \\
p \text { value of paired } t \text { test }\end{array}$ & $\begin{array}{l}\text { Geometric mean of } \\
\text { intensities of a } \\
\text { module of pre- } \\
\text { and post-treatment }\end{array}$ & $\begin{array}{l}\text { Unadjusted } \\
p \text { value of } \\
\text { paired } t \text { test }\end{array}$ & \\
\hline ESR1 & -23.06 & $1.54 \mathrm{E}-02$ & 18.28 & $6.23 \mathrm{E}-01$ & $9.18 \mathrm{E}-03$ \\
\hline ERGs-GS & -30.79 & $8.58 \mathrm{E}-14$ & -21.96 & $2.85 \mathrm{E}-03$ & $5.81 \mathrm{E}-02$ \\
\hline DiLeoRBloss-GS & -27.61 & $9.81 \mathrm{E}-10$ & -30.64 & $1.41 \mathrm{E}-03$ & $5.43 \mathrm{E}-01$ \\
\hline JClinlnvest2007RBloss-GS & -26.11 & 5.47E-10 & -29.45 & $1.78 \mathrm{E}-03$ & $4.72 \mathrm{E}-01$ \\
\hline CIN70-GS & -25.92 & $3.26 \mathrm{E}-10$ & -28.69 & $1.81 \mathrm{E}-03$ & $5.40 E-01$ \\
\hline E2F4activation-GS & -25.26 & 4.54E-09 & -30.07 & $5.02 \mathrm{E}-03$ & $3.13 \mathrm{E}-01$ \\
\hline GGI-GS & -23.67 & $1.78 \mathrm{E}-09$ & -27.85 & 1.19E-03 & $3.40 \mathrm{E}-01$ \\
\hline ERTarget27-GS & -17.80 & $1.32 \mathrm{E}-15$ & -11.41 & $3.32 \mathrm{E}-02$ & $1.71 \mathrm{E}-02$ \\
\hline $\begin{array}{l}\text { E2FmotifCellCycle } \\
\text { Associated-GS }\end{array}$ & -16.75 & $5.71 \mathrm{E}-09$ & -21.72 & $2.00 \mathrm{E}-03$ & $1.31 \mathrm{E}-01$ \\
\hline E2Factivation-GS & -14.45 & $2.25 E-07$ & -18.20 & 1.93E-02 & $2.62 \mathrm{E}-01$ \\
\hline AURKA-GS & -13.91 & $1.08 \mathrm{E}-07$ & -15.45 & $3.94 \mathrm{E}-03$ & $6.10 \mathrm{E}-01$ \\
\hline Gene70-GS & -9.37 & $1.97 \mathrm{E}-07$ & -12.34 & $6.76 \mathrm{E}-03$ & $1.98 \mathrm{E}-01$ \\
\hline SET-GS & -9.34 & $1.55 E-05$ & -2.08 & 5.69E-01 & $8.73 E-03$ \\
\hline PTEN-GS & -7.55 & $1.44 \mathrm{E}-06$ & -8.81 & $3.62 \mathrm{E}-02$ & $5.38 \mathrm{E}-01$ \\
\hline ESR1.2-GS & -5.82 & 3.01E-04 & -0.46 & 8.49E-01 & 1.10E-02 \\
\hline ESR1.1-GS & -5.40 & $2.99 \mathrm{E}-03$ & 0.29 & $9.29 \mathrm{E}-01$ & 1.50E-02 \\
\hline MYC-GS & -4.36 & $1.98 \mathrm{E}-04$ & -3.54 & $2.24 \mathrm{E}-01$ & $6.02 \mathrm{E}-01$ \\
\hline IGF1-GS & -4.15 & $4.59 \mathrm{E}-04$ & -4.07 & 7.76E-02 & $9.58 \mathrm{E}-01$ \\
\hline VEGF-GS & -3.85 & 3.33E-02 & -0.21 & $9.48 \mathrm{E}-01$ & $1.09 \mathrm{E}-01$ \\
\hline GDNF-GS & -3.41 & $1.40 \mathrm{E}-01$ & -5.23 & $4.25 E-01$ & $5.71 \mathrm{E}-01$ \\
\hline obesity-GS & -3.08 & $2.40 \mathrm{E}-02$ & -1.72 & $5.64 \mathrm{E}-01$ & 4.55E-01 \\
\hline E2F3-GS & -2.89 & 5.01E-05 & -3.79 & $2.62 \mathrm{E}-02$ & $3.45 E-01$ \\
\hline PI3K-GS & -1.80 & $3.19 E-03$ & -3.11 & $6.69 \mathrm{E}-02$ & $1.23 \mathrm{E}-01$ \\
\hline SRC-GS & -1.69 & $2.83 \mathrm{E}-01$ & -1.62 & $6.46 \mathrm{E}-01$ & $9.74 \mathrm{E}-01$ \\
\hline AKT/mTOR-GS & -1.62 & 4.57E-02 & -1.95 & $3.31 \mathrm{E}-01$ & $7.51 \mathrm{E}-01$ \\
\hline RAS-GS & -1.47 & $1.93 \mathrm{E}-01$ & -0.47 & $8.51 \mathrm{E}-01$ & $5.04 \mathrm{E}-01$ \\
\hline BetaCatenin-GS & -1.28 & $3.83 \mathrm{E}-01$ & 0.04 & $9.91 \mathrm{E}-01$ & 5.07E-01 \\
\hline WntTarget34-GS & -0.30 & $8.90 \mathrm{E}-01$ & -2.56 & $6.50 \mathrm{E}-01$ & 4.28E-01 \\
\hline ERBB2-GS & 0.27 & $8.88 \mathrm{E}-01$ & -0.88 & $8.60 \mathrm{E}-01$ & $6.55 E-01$ \\
\hline PIK3CA-GS & 0.39 & 7.20E-01 & 1.77 & $3.99 \mathrm{E}-01$ & $3.42 \mathrm{E}-01$ \\
\hline STAT1-GS & 0.79 & $8.27 \mathrm{E}-01$ & -7.73 & $2.98 \mathrm{E}-01$ & $6.99 \mathrm{E}-02$ \\
\hline CASP3-GS & 1.37 & 5.57E-01 & -1.18 & $8.48 \mathrm{E}-01$ & $3.82 \mathrm{E}-01$ \\
\hline Bcell-GS & 1.71 & $6.92 \mathrm{E}-01$ & -7.38 & $3.51 \mathrm{E}-01$ & $7.71 \mathrm{E}-02$ \\
\hline MacTh1-GS & 2.72 & 4.94E-01 & 0.20 & $9.79 E-01$ & $6.38 \mathrm{E}-01$ \\
\hline Tcell-GS & 2.83 & $5.38 \mathrm{E}-01$ & -6.13 & 4.73E-01 & $1.12 \mathrm{E}-01$ \\
\hline Inflammatory-GS & 2.86 & $4.92 \mathrm{E}-01$ & -4.80 & $5.15 E-01$ & $1.55 \mathrm{E}-01$ \\
\hline Immune.1-GS & 3.07 & $5.24 \mathrm{E}-01$ & -5.34 & $6.10 \mathrm{E}-01$ & 1.49E-01 \\
\hline MAPK-GS & 3.21 & $6.59 \mathrm{E}-03$ & 1.94 & $5.02 \mathrm{E}-01$ & $4.22 \mathrm{E}-01$ \\
\hline Stroma.2.PLAU-GS & 6.57 & 4.65E-02 & 4.54 & $5.14 \mathrm{E}-01$ & $6.34 \mathrm{E}-01$ \\
\hline Stroma.1-GS & 20.71 & 1.17E-02 & 21.87 & $1.61 \mathrm{E}-01$ & $9.18 \mathrm{E}-01$ \\
\hline
\end{tabular}


Table 3 Relative changes in the expression of gene signatures in response to the 2-week Al treatment of the HER2- and HER2+ tumours. (Continued)

\begin{tabular}{|c|c|c|c|c|c|}
\hline \multirow[t]{2}{*}{ Module name } & \multicolumn{2}{|l|}{ HER2-negative } & \multicolumn{2}{|l|}{ HER2-positive } & \multirow{2}{*}{$\begin{array}{l}\text { Significance of the } \\
\text { difference betweer } \\
\text { two changes in } \\
\text { expression } \\
\text { (HER2-vs HER2+) }\end{array}$} \\
\hline & $\begin{array}{l}\% \Delta \text { of geometric } \\
\text { mean of intensities } \\
\text { of a module of pre- } \\
\text { and post-treatment }\end{array}$ & $\begin{array}{l}\text { 2-sided unadjusted } \\
p \text { value of paired } t \text { test }\end{array}$ & $\begin{array}{l}\text { Geometric mean of } \\
\text { intensities of a } \\
\text { module of pre- } \\
\text { and post-treatment }\end{array}$ & $\begin{array}{l}\text { Unadjusted } \\
p \text { value of } \\
\text { paired } t \text { test }\end{array}$ & \\
\hline TP53-GS & 29.90 & $6.45 \mathrm{E}-10$ & 29.38 & $5.59 \mathrm{E}-03$ & $9.44 \mathrm{E}-01$ \\
\hline PAGs & -4.40 & $6.44 \mathrm{E}-06$ & -6.23 & 2.06E-02 & 1.37E-01 \\
\hline
\end{tabular}

Significant difference test of the changes between HER2- and HER2+ tumours. The increase of TP53-GS score after Al treatment is associated with the TP53 wild-type status

STAT1-GS treatment score showed a significant association with high residual Ki67 ( $r=0.25, p=5.64 \mathrm{E}-03)$, as did the Inflammatory-GS and MacTh1-GS (Table 4).

\section{Association of the change in pre-selected gene signature scores with changes in Ki67 and residual Ki67}

Unsurprisingly, ten of the changes in signature scores that were significantly directly correlated with Ki67 change were proliferation-associated GSs. However, of particular note, reduction in the expression of the ERGsGS was also directly associated with greater Ki67 suppression and low residual Ki67. In addition, increase in ERBB2-GS score was significantly associated with both greater Ki67 suppression and lower residual Ki67 after AI therapy, possibly as an immediate compensatory resistance mechanism (Table 5; Additional file 2: Table S14; Additional file 11: Figure S8a; Additional file 8: Table S20A). The change in ESR1 expression was significantly associated with the change in all the modules measuring oestrogen signalling (SET-GS, $r=0.72$; ESR11-GS, $r=0.69$; ESR1-2-GS, $r=0.59$; ERTarget27-GS, $r=$ 0.39; ERGs-GS, $r=0.36$; all $p<0.0001$ ).

\section{HER2-positive tumours}

Class comparison of the mean changes between the 26 AI-treated HER2+ tumours and 8 HER2+ control tumours identified 71 annotated genes, which were significantly changed by AI therapy ( $n=19$ upregulated, $n=52$ downregulated). (Fig. 3b; Additional file 2: Table S15). Pathway analysis of the 71 genes identified 7 canonical pathways as being significantly enriched (adjusted $p$ value $<0.05$; Additional file 12: Figure S9). Activation of the top pathway, mitotic roles of Polo-like kinase, was indicated as being significantly reduced by oestrogen deprivation consistent with the partial reduction in Ki67 for almost all of the HER2+ tumours and with the changes in proliferation-related genes in the HER2cohort.

To identify any significant differences between HER2+ and HER2 - tumours in their molecular response to AIs, we compared the AI-induced gene changes between the two groups (Additional file 2: Table S12). Seven of the 10 top downregulated genes in the HER2+ group were in the top 13 downregulated genes in HER2- tumours. The top upregulated gene NDP in the HER2- group was also the top upregulated in HER2+ tumours. Proliferation-associated and cell cycle genes were suppressed to a similar extent in both cohorts despite the difference in Ki67 suppression.

The classical oestrogen-regulated genes were suppressed to a significantly lesser extent by AI treatment in the HER2+ tumours, for example, downregulation of TFF1, TFF3, CCND1, and PGR was significantly less ( $p$ 's for difference $=0.0027,0.0001,0.035$, and 0.0034, respectively). In contrast to the decrease in ESR1 levels seen in the HER2 - tumours, in HER2+ tumours, ESR1 gene expression was not significantly changed $(p=0.009$ for the difference between the groups). The GSs that measure oestrogen signalling (ERTarget27-GS, SET-GS, ESR1.2-GS, ESR1.1-GS) were also significantly less suppressed by AI in HER2+ tumours (Table 3). Again, in contrast with HER2- tumours, ESR1 expression was significantly correlated with the change in $\mathrm{Ki67}(r=-0.61$, $p=2.57 \mathrm{E}-03$ ) being among the 25 genes whose baseline expression correlated with better Ki67 response (Additional file 5: Figure S3c; Additional file 2: Table S16). ESR1 was among the 54 genes whose high baseline expression correlated with low residual proliferation in HER2+ tumours $(r=-0.62, p=2.19 \mathrm{E}-03)$ while there were no such significant relationships with ESR1 in the HER2- group (Additional file 5: Figure S3d; Additional file 2: Table S17).

\section{Association of genes and pre-selected signatures in HER2+ tumours}

Analysis of the pre-selected signatures in the HER2+ cohort showed similar results to those observed in the HER2 - tumours (Additional file 7: Figure S5b, Additional file 10: Figure S7b, Additional file 11: Figure S8b; Additional file 8: Table S18B, S19B, S20B). In those cases where there were differences between the relationships in HER2+ and HER2-, the $p$ values were only ever moderately significant. Given the size of the HER2+ group and the multiple tests conducted, we did not pursue these further. 
Table 4 Spearman rank correlation of surgery ESR1 expression/pre-selected gene signature scores and percentage of 2-week change in Ki67/residual Ki67 level in HER2- tumours

\begin{tabular}{|c|c|c|c|c|c|c|c|}
\hline \multirow{2}{*}{\multicolumn{2}{|c|}{ Surgery gene signature scores }} & \multicolumn{6}{|c|}{ HER2- $(n=135)$} \\
\hline & & \multicolumn{3}{|c|}{ Change in Ki67 $(n=121)$} & \multicolumn{3}{|c|}{ Residual Ki67 $(n=124)$} \\
\hline Signature name & Reference & Rho & $p$ value & FDR & Rho & $p$ value & FDR \\
\hline ESR1 & & -0.19 & $3.42 \mathrm{E}-02$ & $4.62 \mathrm{E}-02$ & -0.17 & $6.53 \mathrm{E}-02$ & $6.53 \mathrm{E}-02$ \\
\hline TP53-GS & Coutant et al. & -0.47 & 7.43E-08 & $6.50 \mathrm{E}-07$ & -0.54 & $6.61 \mathrm{E}-11$ & 3.57E-10 \\
\hline ERTarget27-GS & VerhaeghCR2014TableS2 & -0.26 & $3.96 \mathrm{E}-03$ & $8.22 \mathrm{E}-03$ & -0.25 & $5.25 \mathrm{E}-03$ & 7.46E-03 \\
\hline SET-GS & Symmans et al. & -0.25 & $5.38 \mathrm{E}-03$ & $1.04 \mathrm{E}-02$ & -0.3 & $7.82 \mathrm{E}-04$ & $1.41 \mathrm{E}-03$ \\
\hline ESR1.2-GS & Desmedt et al. & -0.24 & $8.58 \mathrm{E}-03$ & $1.32 \mathrm{E}-02$ & -0.27 & $2.52 \mathrm{E}-03$ & 4.00E-03 \\
\hline ESR1.1-GS & Mackay et al. & -0.23 & 1.15E-02 & $1.63 \mathrm{E}-02$ & -0.29 & $1.34 \mathrm{E}-03$ & 2.26E-03 \\
\hline ERGs-GS & Dunbier et al. & -0.09 & $3.56 \mathrm{E}-01$ & $3.70 \mathrm{E}-01$ & -0.21 & $1.96 \mathrm{E}-02$ & 2.21E-02 \\
\hline PIK3CA-GS & Loi et al. & -0.05 & $5.53 \mathrm{E}-01$ & $5.53 \mathrm{E}-01$ & -0.18 & 4.07E-02 & 4.23E-02 \\
\hline MacTh1-GS & Iglesia et al. & 0.088 & $3.39 \mathrm{E}-01$ & $3.66 \mathrm{E}-01$ & 0.199 & 2.64E-02 & $2.85 \mathrm{E}-02$ \\
\hline Inflammatory-GS & Dunbier et al. & 0.116 & $2.05 E-01$ & $2.31 \mathrm{E}-01$ & 0.22 & $1.43 \mathrm{E}-02$ & 1.68E-02 \\
\hline GDNF-GS & Morandi et al. & 0.116 & $2.04 \mathrm{E}-01$ & $2.31 \mathrm{E}-01$ & 0.254 & 4.40E-03 & $6.60 \mathrm{E}-03$ \\
\hline obesity-GS & Creighton et al. & 0.134 & $1.43 \mathrm{E}-01$ & $1.76 \mathrm{E}-01$ & 0.239 & 7.61E-03 & 9.34E-03 \\
\hline Immune.2.STAT1-GS & Desmedt et al. & 0.158 & $8.26 \mathrm{E}-02$ & $1.06 \mathrm{E}-01$ & 0.247 & $5.64 \mathrm{E}-03$ & 7.61E-03 \\
\hline E2F3-GS & Bild et al. & 0.237 & $8.79 \mathrm{E}-03$ & $1.32 \mathrm{E}-02$ & 0.24 & $7.38 \mathrm{E}-03$ & $9.34 \mathrm{E}-03$ \\
\hline IGF1-GS & Creighton et al. & 0.24 & 8.06E-03 & $1.32 \mathrm{E}-02$ & 0.303 & $6.22 \mathrm{E}-04$ & 1.20E-03 \\
\hline AKT/mTOR-GS & Majumder et al. & 0.249 & $5.83 \mathrm{E}-03$ & $1.05 \mathrm{E}-02$ & 0.362 & $3.63 \mathrm{E}-05$ & 7.54E-05 \\
\hline PTEN-GS & Saale at al. & 0.286 & $1.49 \mathrm{E}-03$ & $3.35 \mathrm{E}-03$ & 0.392 & $6.68 \mathrm{E}-06$ & 1.50E-05 \\
\hline PI3K-GS & Creighton 2010 & 0.291 & $1.21 \mathrm{E}-03$ & 2.97E-03 & 0.413 & $1.92 \mathrm{E}-06$ & 4.71E-06 \\
\hline AURKA-GS & Desmedt et al. & 0.32 & $3.53 \mathrm{E}-04$ & $9.53 \mathrm{E}-04$ & 0.427 & 7.36E-07 & 1.99E-06 \\
\hline E2Factivation-GS & Miller et al. & 0.323 & $3.08 \mathrm{E}-04$ & $9.24 \mathrm{E}-04$ & 0.432 & $5.39 \mathrm{E}-07$ & $1.62 \mathrm{E}-06$ \\
\hline E2FmotifCellCycleAssociated-GS & Miller et al. & 0.402 & $4.79 \mathrm{E}-06$ & $1.62 \mathrm{E}-05$ & 0.454 & $1.22 \mathrm{E}-07$ & 4.12E-07 \\
\hline Gene70-GS & van 't Veer et al. & 0.431 & $8.22 \mathrm{E}-07$ & $3.17 \mathrm{E}-06$ & 0.546 & $5.64 \mathrm{E}-11$ & 3.57E-10 \\
\hline CIN70-GS & Carter et al. & 0.442 & $3.89 \mathrm{E}-07$ & $1.75 \mathrm{E}-06$ & 0.529 & $2.79 \mathrm{E}-10$ & $1.08 \mathrm{E}-09$ \\
\hline E2F4activation-GS & Guerrero-Zotano et al. & 0.454 & $1.73 \mathrm{E}-07$ & $9.34 \mathrm{E}-07$ & 0.535 & $1.51 \mathrm{E}-10$ & $6.80 \mathrm{E}-10$ \\
\hline GGI-GS & Sotiriou et al. & 0.462 & 9.63E-08 & $6.50 \mathrm{E}-07$ & 0.571 & $4.52 \mathrm{E}-12$ & $6.10 E-11$ \\
\hline JClinInvest2007RBloss-GS & Bosco et al. & 0.491 & $1.12 \mathrm{E}-08$ & $1.51 \mathrm{E}-07$ & 0.545 & $5.89 \mathrm{E}-11$ & 3.57E-10 \\
\hline DiLeoRBloss-GS & Malorni et al. & 0.526 & $5.61 \mathrm{E}-10$ & $1.51 \mathrm{E}-08$ & 0.584 & $1.08 \mathrm{E}-12$ & $2.92 \mathrm{E}-11$ \\
\hline
\end{tabular}

TP53-GS surgery score was the strongest inversely associated with the change in Ki67 and residual Ki67. The inverse correlation relates to high TP53-GS score being associated positively with TP53 wild-type status

\section{Discussion}

AIs are well-established as the most effective and therefore most frequently used endocrine agents for treating $\mathrm{ER}+\mathrm{BC}$ in postmenopausal women [5]. Despite the efficacy of AIs, many patients recur with either de novo or acquired AI-resistant disease. Molecular characterisation of the resistance phenotype(s) is critical for enhanced control of the disease. In this study, we report the largest sample set describing the genome-wide transcriptional and related antiproliferative effects of AIs. In addition, for the first time, we have been able to correct for artefactual transcriptional changes that occurred in the control group in the absence of any treatment. We have described those artefactual changes in detail elsewhere and discussed the likely causes $[13,15]$. Most importantly, had we been unable to correct for them; the most significantly and most quantitatively changed genes in the AI-treated group would have been accepted in error as due to AI treatment while they were in fact entirely related to tissue processing [13]. Our analyses applied rigorous statistical methods using Benjamini-Hochberg procedure where appropriate to calculate the FDR in order to adjust for multiple testing.

Our assessment of the biologic response/resistance of the tumours to AI was based on Ki67. It is important to appreciate the significance of the different endpoints and their validity for that purpose. Proportional or percentage change in Ki67 has been validated as reflecting the 


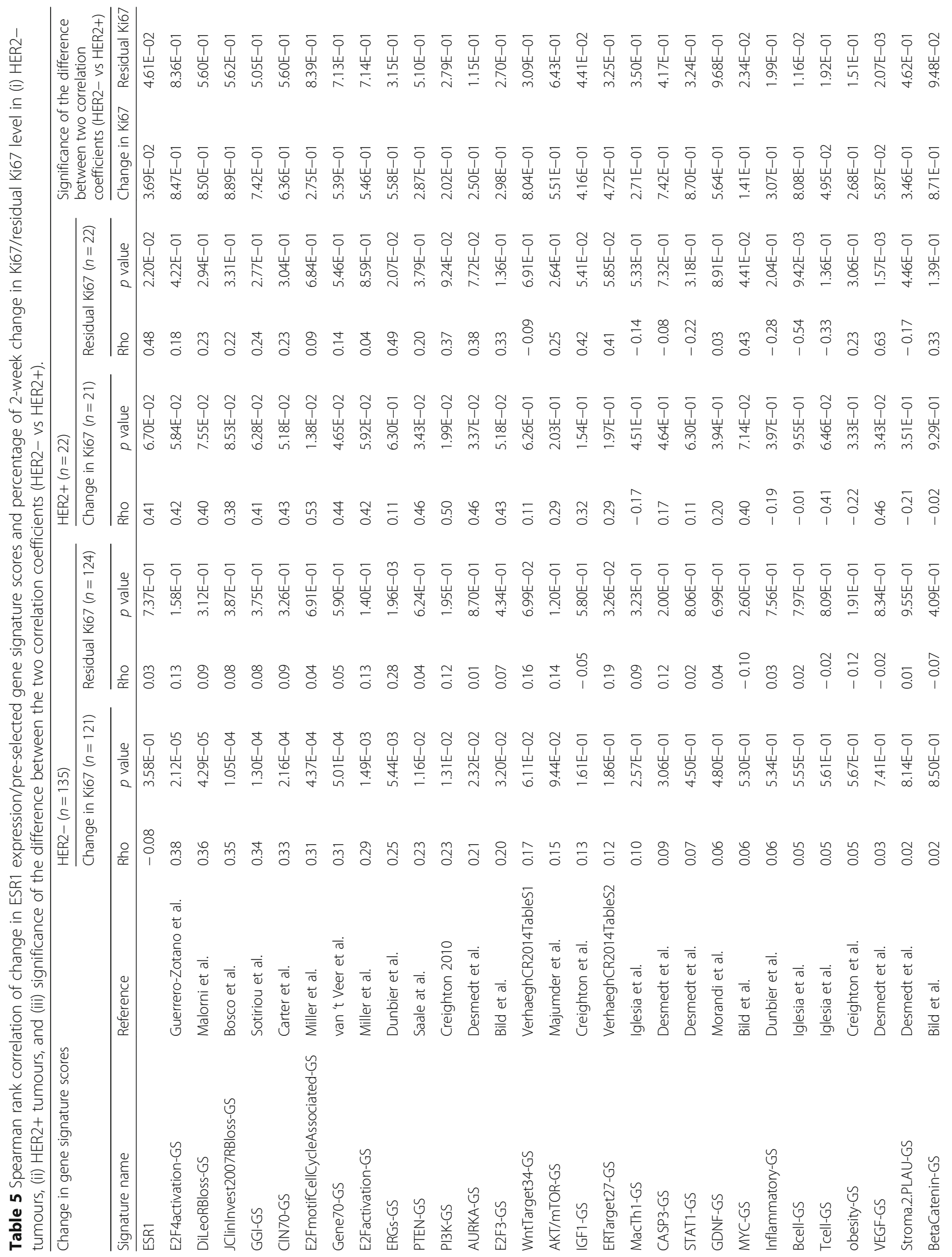




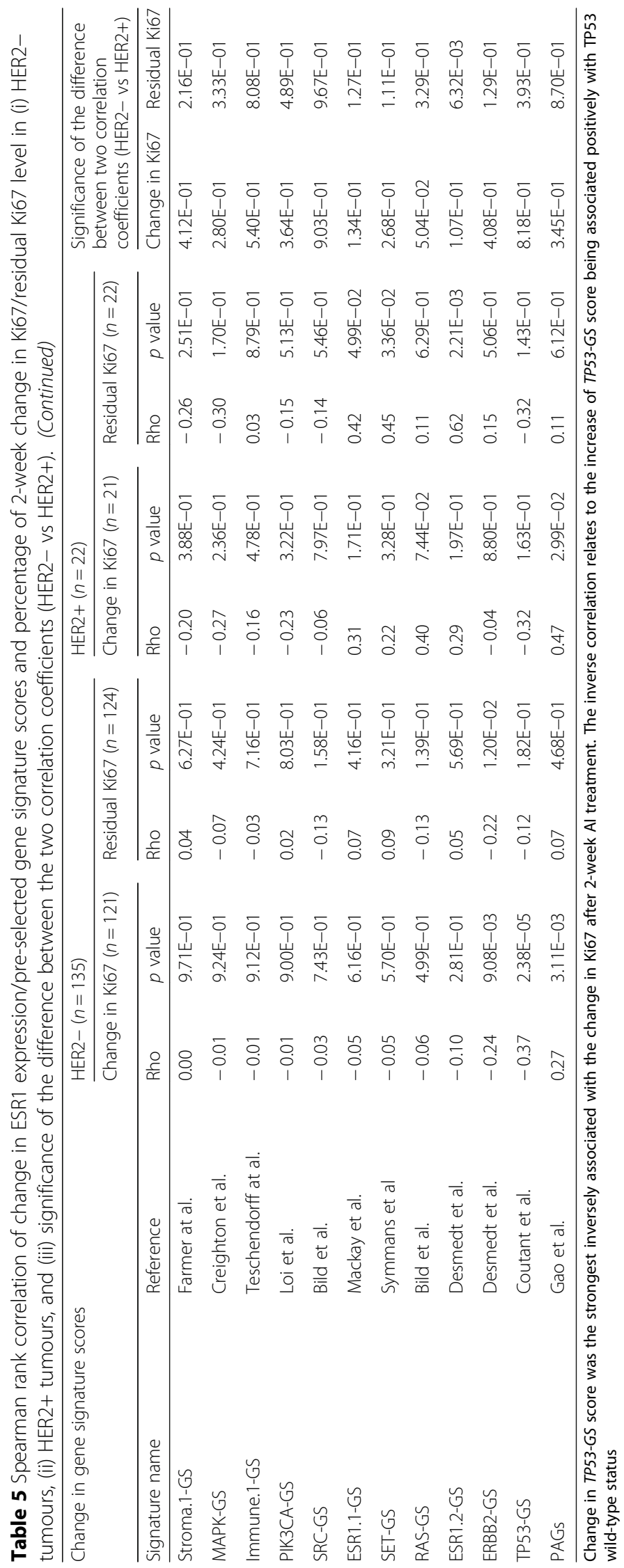


degree of benefit (or response) to AI [6-9] and is the relevant parameter for considering mechanisms of response/resistance to AI therapy. The 2-week (residual) value of Ki67 is determined in part by the proportional response to the AI but also by the pretreatment value; the value correlates with the residual risk of recurrence on the endocrine therapy [10] and is relevant as a marker of the value/need to apply additional adjuvant therapy, irrespective of whether or not there has been a good or poor proportional antiproliferative response to the AI. Continued or altered (rewired) signalling in the residual tissue may be more relevant to the targeting of the additional agents than baseline expression. It should be noted that while our sample set was drawn from the POETIC trial, we make no claims for it being a representative subset (although it may be). Rather, the design of POETIC and availability of the set of RNAlater-stored samples provided the opportunity for us to undertake the molecular analyses described; the relevance of our observations to ER+ breast cancer in general may be considered by reference to the demographics of this subset.

In the HER2- group, we confirmed that high baseline signature scores of IGF1-GS, STAT1-GS, and GDNF-GS were associated with poor antiproliferative response when Ki67 change was dichotomised [12, 22]. Although we validated STAT1-GS, which represents features of immune activity as being associated with AI resistance, there was no significant association between Inflammatory-GS and the change in Ki67. This is somewhat in contrast to our previous report in a smaller mixed HER2-/HER2+ set in which both these signatures were predictive of poor AI response of tumours $[11,12]$. The significantly high baseline ERBB2-GS in AI non-responders suggests tumours with high HER2 signalling activity even in HER2- tumours were predictive of poor response. This is consistent with the observation of poor response to letrozole alone and improved outcome with added lapatinib in the HER2enriched subtype of HER2- metastatic BC [36]. Further assessment of the interaction between this subtype and response to endocrine therapy is now underway in the much larger formalin-fixed set of tissues from POETIC. The strong correlations between several baseline signature scores and the residual Ki67 confirmed the high proliferation (AURKA-GS, PTEN-GS, Gene70-GS, GGIGS, CIN70-GS), RB-loss (Rbloss-GS, DiLeoRBloss-GS), high E2F activation (E2F4activation-GS, E2FactivationGS), and TP53 dysfunction (TP53-GS) were associated with high-oestrogen independent residual proliferation irrespective of whether the tumour showed an antiproliferative response to AI [12, 17-21].

We and others have previously described that HER2 positivity impedes the antiproliferative effect of endocrine therapy $[26,27]$. The resultant major difference in the changes in Ki67 suppression seen here between the HER2+ and HER2- group led us to consider the HER2 subgroups separately. This allowed us to describe the substantial differences in oestrogen signalling that occurred between them. In HER2+ but not HER2- tumours, baseline ESR1 expression was significantly correlated with the change in Ki67 levels, and while those ESR1 levels were suppressed in HER2 - tumours, they were not significantly changed in HER2+ tumours; expression of oestrogen-regulated genes and ER-related gene modules was also changed less in HER2+ than in HER2- tumours. This difference could be explained by the decrease in oestrogen signalling in the HER2- tumours being in part dependent on the lower ESR1 levels on-treatment and not just by the oestrogen deprivation with the AI. Alternatively, or in addition, the apparent persistent oestrogen signalling in HER2+ tumours might result from ligand-independent activation of ER by HER2. This highlights the complex crosstalk between HER2 and ER [37].

Assessment of the gene expression at baseline in the HER2- cohort to identify de novo biomarkers of resistance revealed a very marked heterogeneity between tumours with no new patterns of expression being associated with changes in Ki67. However, intrinsic subgrouping did reveal that luminal B and particularly the small number of non-luminal tumours showed less Ki67 suppression and greater residual Ki67 levels than luminal A tumours. This is somewhat in contrast to our report in a smaller earlier set of tumours in which the proportional change in Ki67 was found to be similar between luminal $\mathrm{A}$ and $\mathrm{B}$ tumours although the residual level of Ki67 was higher in the latter [11,38].

Unsurprisingly, it is clear that proliferation and cell cycle-associated pathways dominated the gene signatures found to change with $\mathrm{AI}$ and also to be associated with residual Ki67. However, we also found that the baseline expression of several proliferation-related gene signatures was also related to the change in Ki67. This is consistent with the greater preponderance of luminal B and non-luminal tumours with a poor change in Ki67.

In contrast to the many cell cycle genes that were decreased in activity in parallel with the decrease in proliferation, CCND2 and CDK6 were increased. CDK4/6 inhibitors are now in widespread use in the treatment of ER+ metastatic BC and are in large clinical trials in primary $\mathrm{BC}$, in each case in combination with endocrine therapy. It was also notable that the most prominent genes in the canonical pathways were $C D K 2$ and CCNEs which are critical to triggering the G1- to S-phase transition. As previously reported, on- 
treatment E2F signatures were among those most strongly associated with residual Ki67 [19, 39], and the TP53-GS that reflects wild-type TP53 function showed the highest correlation with lower residual Ki67. Assessment of the early impact by AIs on each of these factors may be relevant to the success or not of CDK4/6 inhibition when combined with an AI. This argues for an initial treatment with an AI before the introduction of the CDK4/6 inhibitor. We are pursuing this concept in the design of a new clinical trial of the adjuvant use of CDK4/6 inhibition in high-risk ER+ disease (POETIC-A).

A particularly novel finding was that $A C A D V L$ baseline expression was the best predictor of both decrease in Ki67 and of low residual Ki67, and its expression was significantly higher in responder and CCCA tumours. In silico analysis of the $\mathrm{BC}$ dataset reveals that the lower baseline expression of $A C A D V L$ was associated with poor relapse-free survival in ER+ patients [40]. The gene encodes a very long chain-specific acyl-CoA dehydrogenase, mitochondrial (VLCAD) enzyme, a key enzyme of the mitochondrial fatty acid $\beta$-oxidation (FAO) pathway. A recent study [41] revealed that VLCAD interacts with the BH3 domain of MCL-1 via a non-canonical mechanism, which is associated with chemoresistance in human cancer and merits further study.

Two other novel findings were the high baseline expression of (i) PERP and YWHAQ as the most significantly associated with poor AI response, and (ii) NEK2 was most strongly associated with high residual proliferation. In silico analysis of the $\mathrm{BC}$ dataset reveals that high baseline expression of YWHAQ and NEK2 have been reported to be associated with poor relapse-free survival in an ER+/HER2- setting for the patients receiving endocrine therapy and no chemotherapy [40]. Furthermore, the expression of YWHAQ and NEK2 was significantly higher in luminal B compared to luminal A tumours in TCGA ER+/HER2- tumours [42]. Together, these findings suggest that the poor prognosis associated with these two genes may be at least partly due to an association with endocrine resistance. PERP, an apoptosisassociated target of p53, is a novel member of the PMP22 family. A recent study [43] revealed that PERP is lost in more aggressive sparsely granulated human growth hormone pituitary tumours, and its loss and associated desmosomal instability may be an early driver of tumour progression. However, its significant association with poor antiproliferative response to AIs in ER+/HER2- tumours has not been previously reported and requires validation prior to further study.

\section{Conclusions}

It is clear from the above that our work identifies the possible involvement of multiple pathways in de novo resistance to AIs, some but not all of which have previously been described. However, there are other pathways whose baseline activity is unrelated to resistance but whose expression is modified or rewired within the first 2 weeks and at that stage is related to residual proliferation.

While the number of cases described is the largest reported to date and is sufficient to identify the possible involvement of each of the pathways described, their relative importance will require assessment in a yet larger population.

Overall, we conclude that there is a high degree of heterogeneity between tumours in their adaptive response to oestrogen deprivation; however, in this study, all appeared to converge on cell cycle regulation. Our data highlighting the relationship between the E2F signature and residual Ki67 along with the earlier proposal by Miller et al. [19] that on-treatment evaluation of this signature could indicate enhanced sensitivity to CDK4/6 inhibition suggests that it merits prospective evaluation in a clinical setting. This is a hypothesis that we will be testing in a major new national adjuvant trial, POETIC$\mathrm{A}$, in which patients with early ER+ breast cancer whose tumour continues to show high Ki67 expression after 2 weeks AI will be randomised to additional CDK4/6 inhibition or not.

\section{Supplementary information}

Supplementary information accompanies this paper at https://doi.org/10. 1186/s13058-019-1223-z.

Additional file 1. Supplementary information. Additional description of the materials and methods.

Additional file 2. Table S1. Published gene-signatures. Table S2. Study endpoints. Table S3. Study demographics. Table S4. List of patients and their status of HER2, Ki67 and CCCA. Table S5. Ki67 data summary. (A) Percentage change in Ki67 expression after 2-weeks Al-treatment. (B) Anti-proliferative response summary. (C) Summary of number of tumours that reached CCCA. Table S6. Genes whose baseline expression significantly correlated with Change.Ki67 $(p<0.005)$ in HER2- group. Table S7. Unpaired t-test of significance for the difference between two-group means: i) non-responders vs responders; ii) noCCCAs vs CCCAs in HER2group. Table S8. Genes whose baseline expression significantly correlated with residual Ki67 $(p<0.005)$ in HER2- group. Table S9. Pathway analysis of genes in Table S8. Table S10. Genes whose baseline expression is significantly different $(p<0.001)$ between CCCA and noCCCA in HER2group. Table S11. Genes significantly regulated by Al with $p<0.005$ by univariate Two-sample T-test in HER2- group. Table S12. Top $20 \mathrm{Al}$ downregulated / Al-upregulated genes, and additional Al-regulated genes of interest identified from HER2- paired tumours. Genes were ranked by fold-change ( $F C$ ). The Significantly different ( $p$-value) derived from Mann-Whitney test comparing the relative change in expression of a given gene in the HER2- group versus the HER2+ group. $n s: p>=0.05$. Table S13. Enriched canonical pathways of the significantly Al-regulated genes in Table S11. Table S14. Correlations of the change in ESR1 / gene-signatures and change in Ki67 / residual-Ki67 in i) HER2- group, ii) HER2+ group, iii) Significance of the difference between the 2 correlation-coefficients. Table S15. Genes significantly regulated by Al with $p<0.005$ by univariate Two-sample T-test in HER2+ group. Table S16. Genes whose baseline expression significantly correlated with Change.Ki67 $(p<0.005)$ in HER2+ group. Table S17. Genes whose baseline 
expression significantly correlated with residual-Ki67 $(p<0.005)$ in HER2+ group.

Additional file 3: Figure S1. Consort diagram showing derivation of samples for microarray analysis and Ki67 measurement. In total, RNA was extracted from 861 RNAlater stored core-cuts and 605 RNA samples with RNA integrity number (RIN) $>4$ and RNA $>500$ ng were sent for profiling. Samples were excluded due to lack of adequate estradiol suppression, RIN $<4$ when profiling, or due to gene expression data of poor quality. "Pairs" indicates a tumour with matched baseline and surgery expression data; B (baseline) indicates a tumour with baseline expression data or baseline Ki67 value; $S$ (surgery) indicates a tumour with surgical expression data or on-treatment Ki67. *Expression QC (quality control): samples with fraction of detection rate $<30 \%$ or detected by lumi.outlier function from lumi $R$ package as outlier were excluded.

Additional file 4: Figure S2. Heatmap (Pearson, complete) of 123 genes whose baseline expression significantly correlated with Change.Ki67 ( $p<$ 0.005) based on 155 HER2- of the 178 Al-treated samples. The gene expression across 155 samples was centred and scaled. Red denotes the gene expression in a sample is greater than the mean, blue denotes less than the mean. The tumours are ordered according to the degree of change in Ki67.

Additional file 5: Figure S3. Scatter plot of baseline gene expression and Ki67 values. (a) ESR1 baseline expression and change in Ki67 of HER2- tumours; (b) ESR1 baseline expression and residual Ki67 of HER2tumours; (c) ESR1 baseline expression and change in Ki67 of HER2+ tumours; (d) ESR1 baseline expression and residual Ki67 of HER2+ tumours.

Additional file 6: Figure S4. Pathway analysis of the list of 123 genes whose baseline expression correlated with change in Ki67 in the HER2tumours by Spearman correlation at a p-value of $<0.005$.

Additional file 7: Figure S5. Heatmap of Spearman Rank Correlation Matrix ( $r$-value and $p$-value) of baseline gene signature scores and percentage of 2-week change in Ki67 and residual Ki67 expression. r-values bottom, $p$-values top. (a) HER2- tumours, $n=155$. (b) HER2+ tumours, $n=23$.

Additional file 8: Matrices of correlation coefficient and $p$ value. Table S18. Spearman Rank Correlation Matrix ( $r$-value and $p$-value) of baseline gene signature scores and percentage of two-week change in Ki67 and residual Ki67 expression. r-values bottom, p-values top. (a) HER2- tumours, $n=155$ (the Signature name was sorted based on the rho-values of correlations between GS-score and residual.Ki67; (b) HER2+ tumours, $n=23$. Table S19. Spearman correlations ( $r$-value and $p$-value) between ontreatment gene signature scores and i) percentage of two-week change in Ki67 protein expression and ii) residual KI67. r-values bottom, $\mathrm{p}$-values top. (a) HER2- tumours, $n=135$; (b) HER2+ tumours, $n=22$. Table S20. Spearman correlations ( $r$-value and $p$-value) between change in gene signature scores and i) percentage of two-week change in Ki67 protein expression and ii) residual KI67. r-values bottom, p-values top. (a) HER2tumours, $n=135$; (b) HER2+ tumours, $n=22$.

Additional file 9: Figure S6. The 41 of the 902 significantly regulated genes after 2-week of treatment in HER2- tumours, that occurred in at least 3 of the significantly enriched 25 canonical pathways (FDR $<5 \%$ ). Black-color and grey-color indicates presence and absence of a gene in a pathway. The numbers at the second row on the top of the black and grey image indicated number of pathways that a gene occurred. The numbers at the second column on the left-hand side of the black and grep image indicated number of genes occurred in a pathway.

Additional file 10: Figure S7. Heatmap of Spearman correlations ( $r$ value and $p$-value) between on-treatment gene signature scores and i) percentage of 2-week change in Ki67 protein expression and ii) residual KI67. r-values bottom, p-values top. (a) HER2- tumours, $n=135$. (b) HER2+ tumours, $n=22$

Additional file 11: Figure S8. Heatmap of Spearman correlations ( $r$ value and $p$-value) between change in gene signature scores and i) percentage of 2-week change in Ki67 protein expression and ii) residual KI67. r-values bottom, p-values top. (a) HER2- tumours, $n=135$. (b) HER2+ tumours, $n=22$

Additional file 12: Figure S9. Overrepresented pathways (FDR $<5 \%$ ) identified by pathway analysis (IPA) of the 71 differentially expressed and annotated genes derived from HER2+ tumours. Negative z-score shown in blue-colour specifies inhibited pathway after Al-treatment. The yellow line indicates the threshold of adjusted $p$-value $<0.05$.

\section{Acknowledgements}

We thank all participating patients and staff at POETIC centres and ICR-CTSU who contributed to the trial management and data and sample collection, and the independent data monitoring committee and trial steering committee for their oversight of the trial. This work was supported by the Mary-Jean Mitchell Green Foundation, Breast Cancer Now, working in partnership with Walk the Walk and the National Institute for Health Research (NIHR) Biomedical Research Centre at the Royal Marsden NHS Foundation Trust and The Institute of Cancer Research, London. The POETIC trial (C1491/A8671/CRUK/07/ 015, C1491/A15955, C406/A8962), from which samples were obtained for this study, was supported by Cancer Research UK as is ICR-CTSU through its core programme grant

\section{Authors' contributions}

QG analysed the data and drafted the manuscript. ELK extracted the RNA. MC provided the subtypes. JM provided the data and composed Additional file 2: Table S2. VM and AD sectioned and reviewed the histopathology of the samples. KS and DE recorded the samples for the study. AS, HC, EM, EA, and JR were involved in the sample acquisition. MD, $I S$, and JB were involved in the conception and design of POETIC. LAM, RR, and $\mathrm{MD}$ drafted the manuscript. All authors read and approved the final manuscript.

\section{Availability of data and materials}

Global gene expression data supporting the finding from this manuscript was deposited at the NCBI gene expression omnibus (GEO) (http://ncbi.nlm. nih.gov/geo/) with accessions of GSE105777 and GSE126870.

\section{Ethics approval and consent to participate}

Ethical approval for POETIC (Trial Number CRUK/07/015) was provided by NRES Committee London-South-East. All patients consented to molecular analysis of their samples for research purposes.

\section{Consent for publication}

All authors approved the final version of this manuscript.

\section{Competing interests}

$M D$ and LAM receive academic funding from Pfizer, Puma Biotechnology Inc., and AstraZeneca. MD receives honoraria from Myriad Genetics and speaker's bureau of Roche; is a consultant and advisory board member of Radius, GTX, and Orion Pharma; and has received remuneration from the ICR rewards to Inventors Schemes. MCUC has a patent: US Patent No. 9,631,239 with royalties paid. All other authors declare that they have no competing interests.

\section{Author details}

${ }^{1}$ Breast Cancer Now Research Centre, ICR, London, UK. ${ }^{2}$ Ralph Lauren Centre for Breast Cancer Research, Royal Marsden Hospital, London, UK. ${ }^{3}$ Clinical Trials and Statistics Unit, The Institute of Cancer Research, London, UK. ${ }^{4}$ Royal Bournemouth Hospital, Castle Lane East, Bournemouth, UK. ${ }^{5}$ Royal Liverpool University Hospital, 200 London Road, Liverpool, UK. ${ }^{6}$ Queen Elizabeth University Hospital Glasgow, Govan, UK. ${ }^{7}$ Poole General Hospital, Longfleet Road, Dorset, UK. ${ }^{8}$ University of Nottingham, Derby Rd., Nottingham, UK. ${ }^{9}$ Breast Unit, Royal Marsden Hospital, London, UK.

Received: 26 July 2019 Accepted: 4 November 2019 Published online: 31 December 2019

\section{References}

1. Tao Z, Shi A, Lu C, Song T, Zhang Z, Zhao J. Breast Cancer: Epidemiology and Etiology. Cell Biochem Biophys. 2015;72(2):333-8.

2. Dodson A, Parry S, Ibrahim M, Bartlett JM, Pinder S, Dowsett M, et al. Breast cancer biomarkers in clinical testing: analysis of a UK national external quality assessment scheme for immunocytochemistry and in situ hybridisation database containing results from 199300 patients. J Pathol Clin Res. 2018;4(4):262-73. https://doi.org/10.1002/cjp2.112. 
3. Smith IE, Dowsett M. Aromatase inhibitors in breast cancer. N Engl J Med. 2003;348(24):2431-42. https://doi.org/10.1056/NEJMra023246.

4. Chia YH, Ellis MJ, Ma CX. Neoadjuvant endocrine therapy in primary breast cancer: indications and use as a research tool. Br J Cancer. 2010;103(6):75964. https://doi.org/10.1038/sj.bjc.6605845.

5. Early Breast Cancer Trialists' Collaborative G. Aromatase inhibitors versus tamoxifen in early breast cancer: patient-level meta-analysis of the randomised trials. Lancet. 2015;386(10001):1341-52. https://doi.org/10.1016/ S0140-6736(15)61074-1.

6. Dowsett M, Nielsen TO, A'Hern R, Bartlett J, Coombes RC, Cuzick J, et al. Assessment of Ki67 in breast cancer: recommendations from the International Ki67 in Breast Cancer working group. J Natl Cancer Inst. 2011; 103(22):1656-64. https://doi.org/10.1093/jnci/djr393.

7. Dowsett M, Smith IE, Ebbs SR, Dixon JM, Skene A, Griffith C, et al. Short-term changes in Ki-67 during neoadjuvant treatment of primary breast cancer with anastrozole or tamoxifen alone or combined correlate with recurrencefree survival. Clin Cancer Res. 2005;11(2 Pt 2):951s-8s.

8. Ellis MJ, Suman VJ, Hoog J, Goncalves R, Sanati S, Creighton CJ, et al. Ki67 proliferation index as a tool for chemotherapy decisions during and after neoadjuvant aromatase inhibitor treatment of breast cancer: results from the American College of Surgeons Oncology Group Z1031 Trial (Alliance). J Clin Oncol. 2017;35(10):1061-9. https://doi.org/10.1200/JCO.2016.69.4406 Epub 2017 Jan 3.

9. Ellis MJ, Suman VJ, Hoog J, Lin L, Snider J, Prat A, et al. Randomized phase II neoadjuvant comparison between letrozole, anastrozole, and exemestane for postmenopausal women with estrogen receptor-rich stage 2 to 3 breast cancer: clinical and biomarker outcomes and predictive value of the baseline PAM50-based intrinsic subtype--ACOSOG Z1031. J Clin Oncol. 2011; 29(17):2342-9. https://doi.org/10.1200/JCO.2010.31.6950 Epub 2011 May 9.

10. Dowsett M, Smith IE, Ebbs SR, Dixon JM, Skene A, A'Hern R, et al. Prognostic value of Ki67 expression after short-term presurgical endocrine therapy for primary breast cancer. J Natl Cancer Inst. 2007;99(2):167-70. https://doi.org/ 10.1093/jnci/djk020.

11. Dunbier AK, Ghazoui Z, Anderson H, Salter J, Nerurkar A, Osin P, et al. Molecular profiling of aromatase inhibitor-treated post-menopausal breast tumors identifies immune-related correlates of resistance. Clin Cancer Res. 2013. https://doi.org/10.1158/1078-0432.CCR-12-1000.

12. Gao Q, Patani N, Dunbier AK, Ghazoui Z, Zvelebil M, Martin LA, et al. Effect of aromatase inhibition on functional gene modules in estrogen receptor-positive breast cancer and their relationship with antiproliferative response. Clin Cancer Res. 2014;20(9):2485-94. https://doi.org/10.1158/1078-0432.CCR-13-2602.

13. ELo-K QG, Cheang MCU, Morden J, Ribas R, Sidhu K, Evans D, Martins V, Dodson A, Anthony Skene CH, Mallon E, Evans A, Bliss JM, Robertson J, Smith I, Martin L-A, Dowsett M, on behalf of the POETIC Trial Management Group and Trialists. Major impact of sampling methodology on gene expression in estrogen receptor-positive breast cancer. JNCI Cancer Spectrum. 2018;2(Issue 2):pky005. https://doi.org/10.1093/jncics/pky005.

14. Dowsett M, Smith I, Robertson J, Robison L, Pinhel I, Johnson L, et al. Endocrine therapy, new biologicals, and new study designs for presurgical studies in breast cancer. J Natl Cancer Inst Monogr. 2011;2011(43):120-3. https://doi.org/10.1093/jncimonographs/lgr034.

15. Lopez-Knowles E, Gao Q, Cheang MC, Morden J, Parker J, Martin LA, et al. Heterogeneity in global gene expression profiles between biopsy specimens taken peri-surgically from primary ER-positive breast carcinomas. Breast Cancer Res. 2016;18(1):39. https://doi.org/10.1186/s13058-016-0696-2.

16. Wolff AC, Hammond ME, Hicks DG, Dowsett M, MCShane LM, Allison KH, et al. Recommendations for human epidermal growth factor receptor 2 testing in breast cancer: American Society of Clinical Oncology/College of American Pathologists clinical practice guideline update. J Clin Oncol. 2013; 31(31):3997-4013. https://doi.org/10.1200/JCO.2013.50.9984

17. Bosco EE, Wang $Y, X u H$, Zilfou JT, Knudsen KE, Aronow BJ, et al. The retinoblastoma tumor suppressor modifies the therapeutic response of breast cancer. J Clin Invest. 2007;117(1):218-28. https://doi.org/10.1172/ JCI28803.

18. Malorni L, Piazza S, Ciani Y, Guarducci C, Bonechi M, Biagioni C, et al. A gene expression signature of retinoblastoma loss-of-function is a predictive biomarker of resistance to palbociclib in breast cancer cell lines and is prognostic in patients with ER positive early breast cancer. Oncotarget. 2016;7(42):68012-22. https://doi.org/10.18632/oncotarget.12010.

19. Miller TW, Balko JM, Fox EM, Ghazoui Z, Dunbier A, Anderson H, et al. ERalpha-dependent E2F transcription can mediate resistance to estrogen deprivation in human breast cancer. Cancer Discov. 2011;1(4):338-51. https://doi.org/10.1158/2159-8290.CD-11-0101.

20. Guerrero-Zotano AL, Stricker TP, Formisano L, Hutchinson KE, Stover DG, Lee $\mathrm{KM}$, et al. ER(+) breast cancers resistant to prolonged neoadjuvant letrozole exhibit an E2F4 transcriptional program sensitive to CDK4/6 inhibitors. Clin Cancer Res. 2018;24(11):2517-29. https://doi.org/10.1158/1078-0432.CCR-172904

21. Coutant C, Rouzier R, Qi Y, Lehmann-Che J, Bianchini G, Iwamoto T, et al. Distinct p53 gene signatures are needed to predict prognosis and response to chemotherapy in ER-positive and ER-negative breast cancers. Clin Cancer Res. 2011;17(8):2591-601. https://doi.org/10.1158/1078-0432.CCR-10-1045.

22. Morandi A, Martin LA, Gao Q, Pancholi S, Mackay A, Robertson D, et al. GDNF-RET signaling in ER-positive breast cancers is a key determinant of response and resistance to aromatase inhibitors. Cancer Res. 2013;73(12): 3783-95. https://doi.org/10.1158/0008-5472.CAN-12-4265.

23. Yoshihara K, Shahmoradgoli M, Martinez E, Vegesna R, Kim H, Torres-Garcia W, et al. Inferring tumour purity and stromal and immune cell admixture from expression data. Nat Commun. 2013;4:2612. https://doi.org/10.1038/ ncomms3612

24. Gellert P, Segal CV, Gao Q, Lopez-Knowles E, Martin LA, Dodson A, et al. Impact of mutational profiles on response of primary oestrogen receptorpositive breast cancers to oestrogen deprivation. Nat Commun. 2016;7: 13294. https://doi.org/10.1038/ncomms13294.

25. Ma CX, Gao F, Luo J, Northfelt DW, Goetz M, Forero A, et al. NeoPalAna: neoadjuvant palbociclib, a cyclin-dependent kinase $4 / 6$ inhibitor, and anastrozole for clinical stage 2 or 3 estrogen receptor-positive breast cancer Clin Cancer Res. 2017. https://doi.org/10.1158/1078-0432.CCR-16-3206.

26. Dowsett M, Harper-Wynne C, Boeddinghaus I, Salter J, Hills M, Dixon M, et al. HER-2 amplification impedes the antiproliferative effects of hormone therapy in estrogen receptor-positive primary breast cancer. Cancer Res. 2001;61(23):8452-8.

27. Ellis MJ, Tao Y, Young O, White S, Proia AD, Murray J, et al. Estrogenindependent proliferation is present in estrogen-receptor HER2-positive primary breast cancer after neoadjuvant letrozole. J Clin Oncol. 2006;24(19): 3019-25. https://doi.org/10.1200/JCO.2005.04.3034.

28. NIH, U.S. National Library of Medicine. https://ghr.nlm.nih.gov/gene/ ACADVL. Accessed 26 Nov 2019

29. Bièche I, Olivi M, Noguès $C$, Vidaud $M$, Lidereau R. Prognostic value of CCND1 gene status in sporadic breast tumours, as determined by real-time quantitative PCR assays. Br J Cancer. 2002;86(4):580-6.

30. Kaklamani V. A genetic signature can predict prognosis and response to therapy in breast cancer: Oncotype DX. Expert Rev Mol Diagn. 2006;6(6): 803-9. https://doi.org/10.1586/14737159.6.6.803.

31. Clevers H, Nusse R. Wnt/beta-catenin signaling and disease. Cell. 2012; 149(6):1192-205. https://doi.org/10.1016/j.cell.2012.05.012

32. Lynsey McKenzie NM-S, Draper J, Nakjang S, Blair HJ, Wichmann C, Vormoor J, Bonifer C, Lacaud G, Heidenreich O. Identification of CCND2 as a RUNX1/ ETO target Required for leukaemic propagation. Blood. 2016;128(22):835 doi DOI: https://doi.org/.

33. Polyak K, Weinberg RA. Transitions between epithelial and mesenchymal states: acquisition of malignant and stem cell traits. Nat Rev Cancer. 2009; 9(4):265-73. https://doi.org/10.1038/nrc2620.

34. Mallini P, Lennard T, Kirby J, Meeson A. Epithelial-to-mesenchymal transition: what is the impact on breast cancer stem cells and drug resistance. Cancer Treat Rev. 2014;40(3):341-8. https://doi.org/10.1016/..ctrv.2013.09.008.

35. Britschgi A, Duss S, Kim S, Couto JP, Brinkhaus H, Koren S, et al. The Hippo kinases LATS1 and 2 control human breast cell fate via crosstalk with ERalpha. Nature. 2017;541(7638):541-5. https://doi.org/10.1038/nature20829.

36. Prat A, Cheang MC, Galvan P, Nuciforo P, Pare L, Adamo B, et al. Prognostic value of intrinsic subtypes in hormone receptor-positive metastatic breast cancer treated with letrozole with or without lapatinib. JAMA Oncol. 2016;2:1287-94.

37. Ali S, Coombes RC. Endocrine-responsive breast cancer and strategies for combating resistance. Nat Rev Cancer. 2002;2(2):101-12. https://doi.org/10. 1038/nrc721.

38. Perou CM, Sorlie T, Eisen MB, van de Rijn M, Jeffrey SS, Rees CA, et al. Molecular portraits of human breast tumours. Nature. 2000;406(6797):74752. https://doi.org/10.1038/35021093.

39. Giltnane JM, Hutchinson KE, Stricker TP, Formisano L, Young CD, Estrada MV, et al. Genomic profiling of ER(+) breast cancers after short-term estrogen suppression reveals alterations associated with endocrine resistance. Sci Transl Med. 2017;9(402). https://doi.org/10.1126/scitransImed.aai7993. 
40. Gyorffy B, Lanczky A, Eklund AC, Denkert C, Budczies J, Li Q, Szallasi Z. An online survival analysis tool to rapidly assess the effect of 22,277 genes on breast cancer prognosis using microarray data of 1,809 patients. Breast Cancer Res Treat. 2010;123(3):725-31.

41. Escudero S, Zaganjor E, Lee S, Mill CP, Morgan AM, Crawford EB, et al. Dynamic regulation of long-chain fatty acid oxidation by a noncanonical interaction between the MCL-1 BH3 helix and VLCAD. Mol Cell. 2018;69(5): 729-43 e7. https://doi.org/10.1016/j.molcel.2018.02.005.

42. Cancer Genome Atlas N. Comprehensive molecular portraits of human breast tumours. Nature. 2012;490(7418):61-70.

43. Kiseljak-Vassiliades K, Mills TS, Zhang Y, et al. Elucidating the role of the desmosome protein p53 apoptosis effector related to PMP-22 (PERP) in growth hormone tumors. Endocrinology. 2017;158:1450-60.

\section{Publisher's Note}

Springer Nature remains neutral with regard to jurisdictional claims in published maps and institutional affiliations.

Ready to submit your research? Choose BMC and benefit from:

- fast, convenient online submission

- thorough peer review by experienced researchers in your field

- rapid publication on acceptance

- support for research data, including large and complex data types

- gold Open Access which fosters wider collaboration and increased citations

- maximum visibility for your research: over $100 \mathrm{M}$ website views per year

At BMC, research is always in progress.

Learn more biomedcentral.com/submissions 